\title{
EL PROCESO CONSTRUCTIVO DE LA COLEGIATA DE SANTA MARÍA LA MAYOR DE ALCAÑIZ (TERUEL) A TRAVÉS DEL PLEITO ENTRE EL AYUNTAMIENTO Y EL CABILDO. 1771-1779*
}

\author{
The Constructive Process of Collegiate Church Santa Maria \\ la Mayor in Alcañiz (Teruel), through the Lawsuit of the \\ Municipal Government vs. Government Council. 1771-1779
}

\author{
Jorge MARTÍN MARCO \\ Universidad de Zaragoza \\ jorgemartinmarco@unizar.es.
}

Fecha de recepción: 14/11/2019

Fecha de aceptación definitiva: 20/05/2020

RESUMEN: Los conflictos de preeminencia que venían arrastrando el Ayuntamiento de Alcañiz y el Cabildo de la colegial de la ciudad desembocaron en un pleito que fue incoado ante la Real Audiencia de Aragón en 1771 y que se prolongó durante ocho años. Ambas instituciones aportaron diversa documentación sobre su implicación en diferentes empresas artísticas para apoyar sus versiones, y que, en algunos casos, los originales no han llegado hasta nuestros días, por lo que constituyen una importante fuente documental que permite arrojar luz a la historia

* Trabajo realizado en el marco del Proyecto de Investigación I+D «Los diseños de arquitectura de tradición gótica en la Península Ibérica entre los siglos XVII y XVIII. Inventario y catalogación» (HAR2017-85523-P). El autor es investigador en formación del Ministerio de Ciencia e Innovación en el Departamento de Historia del Arte de la Universidad de Zaragoza. Realiza su tesis doctoral sobre arquitectura religiosa en Aragón durante los siglos XVII y XVIII bajo la dirección de los doctores Javier Ibáñez Fernández (Universidad de Zaragoza) y Yolanda Gil Saura (Universidad de Valencia), a quienes agradece las apreciaciones realizadas al texto. 
constructiva de la empresa arquitectónica más importante de la provincia de Teruel en el Setecientos.

Palabras clave: arquitectura barroca; Aragón; Alcañiz; colegiata; fray Atanasio Aznar.

ABSTRACT: The conflicts of preeminence that had been dragging the municipality of Alcañiz and the town council of the city led to a lawsuit that was initiated before the Royal Court of Aragon in 1771 and lasted for eight years. Both institutions provided various documentation on their involvement in different artistic companies to support their versions, and that, in some cases, the originals have not reached our days, so they constitute an important documentary source that sheds light on the constructive history of the most important architectural company in the province of Teruel in the 18th century.

Key words: Baroque architecture; Aragon, Alcañiz; collegiate church; fray Atanasio Aznar.

\section{Para Javier Ibáñez Fernández}

La iglesia de Santa María la Mayor de Alcañiz (Teruel) fue la última de las parroquias alcañizanas que se construyó en época medieval, fundamentalmente, entre los siglos XIII y XIV. Fue elevada al rango de colegial por Benedicto XIII en 1407, acogió diferentes sesiones de las cortes del reino y tras experimentar diversas actuaciones, como la instalación del retablo mayor en torno a $1480^{1} \mathrm{o}$ la construcción de diversas capillas entre finales del Quinientos y la primera mitad del Seiscientos ${ }^{2}$, comenzó un declive a finales de esa centuria que finalizó con su demolición en la primera mitad de $1736^{3}$.

La construcción del nuevo templo colegial a partir de esa fecha desembocó en un conflicto de preeminencias entre el Ayuntamiento de la ciudad y el Cabildo de Santa María la Mayor, que precipitó la incoación de dos pleitos civiles ante la Real Audiencia de Aragón. El primero fue interpuesto por el Cabildo en 17584,

1. IBÁÑEZ FERnÁNDEZ, Javier y MARTín MARCO, Jorge. "El antiguo retablo mayor de la colegiata de Alcañiz (Teruel): Jaime Romeu, Domingo y Tomás Ram. 1470-ca. 1486» (en prensa).

2. Una primera visión a la colegiata medieval en MARTín MARCO, Jorge y GIL BORDÁs, José Ángel. "La antigua iglesia colegial de Alcañiz: un ejemplo de promoción artística en el medievo aragonés». En IBÁÑEZ FERNÁNDEZ, Javier (coord. y ed.). Del mecenazgo a las nuevas formas de promoción artística. Actas del XIV Coloquio de Arte Aragonés. Zaragoza: Prensas de la Universidad de Zaragoza, 2017, pp. 263-280.

3. El acuerdo fue publicado en ThOmson LlisterRi, Teresa. Las artes en el Bajo Aragón en la primera mitad del siglo XVIII. Estudio documental. Alcañiz: Centro de Estudios Bajoaragoneses, 1998, doc. 34, pp. 325-337.

4. Archivo Histórico Provincial de Zaragoza [AHPZ], Pleitos Civiles, J13414-4. 
porque consideraba que el Concejo se entrometía en cuestiones de los eclesiásticos como el tañido de las campanas en celebraciones, funerales o procesiones.

El segundo -el que nos interesa- también fue interpuesto por los eclesiásticos ante la pretensión municipal de colocar el escudo de armas de la ciudad en la fachada del templo y se desarrolló entre 1771 y 1779. Las dos partes proporcionaron diversa documentación para probar su implicación en las obras y el mantenimiento de la colegial tanto medieval como barroca durante su instrucción; y donde, en algunos casos, los originales no han llegado hasta nosotros. En concreto algunas noticias procedentes de protocolos notariales y algunos asientos de las actas municipales celebradas en el Seiscientos ${ }^{5}$, por lo que constituyen una buena fuente para acercarnos a la historia constructiva del edificio.

También resultan de gran valor las descripciones de las trazas de la colegial -que tampoco se han conservado-, de algunos edificios de la ciudad o del propio templo en 1775, y las declaraciones efectuadas por diferentes profesionales de la construcción - maestros albañiles o canteros- que habían participado en la demolición del edificio gótico y en la posterior construcción del nuevo, y que constituyen testimonios de primer orden tanto para acercarnos a la desaparecida colegiata medieval y a los inicios de las obras de la nueva, como para comprender mejor a los protagonistas de la arquitectura alcañizana -y bajoaragonesa en última instancia- del Setecientos.

Al final, tras el dilatado proceso constructivo, la colegiata alcañizana se convirtió en una de las empresas más destacadas del barroco aragonés, donde pueden comprobarse los ecos del Pilar de Zaragoza, trasladados por su tracista, Domingo de Yarza, que se encontraba dirigiendo los trabajos de la basílica zaragozana cuando realizó los diseños. Además, la arquitectura del templo alcañizano tuvo un gran impacto en las empresas constructivas desarrolladas en el Bajo Aragón, y que acabó encontrando fortuna en los territorios limítrofes con el antiguo reino aragonés.

1. El EDIFICIO MEDIEVAl EN LA PRIMERA Mitad DEL SEISCIENTOS: LAS CAPIllas DE SAN JOAQUÍN Y SAN GREGORIO Y LA NUEVA CUSTODIA

Melchor Sierra -mercader de Alcañiz-solicitó permiso al capítulo de la colegial -conformado por el deán y los canónigos- para la construcción de la capilla bajo la advocación de san Joaquín el 7 de enero de $1627^{6}$. El acuerdo le permitía a Sierra levantar el oratorio en el lugar donde estaba situado el armario de los cirios,

5. Las actas más antiguas que han llegado hasta nuestros días son las del periodo comprendido entre 1736 y 1740. Los asientos relativos a las obras de la colegial fueron publicados en ABós Castel, M. ${ }^{a}$ Pilar y Micolau Adell, José Ignacio. "Documentos sobre la participación municipal en la construcción de la Iglesia Colegial de Alcañiz”. Boletín del Centro de Estudios Bajoaragoneses, 1981, 1, pp. 97-106.

6. AHPZ, Pleitos Civiles, J13419-1, pieza 3, ff. 173v-176r. 
«en frente de donde [estaba] reserbado de presente el Santissimo Sacramento», con la posibilidad de utilizar todo el espacio que había "de pilar a pilar». También accedieron a que Sierra colocase una reja de hierro y realizase un carnerario para su entierro y el de su familia fuera del recinto "por ser pequeño el ambito, y lugar».

Por su parte, la iniciativa para realizar una nueva custodia partió del municipio, cuyos representantes se congregaron para resolver la necesidad de materializar un nuevo ostensorio para "las procesiones que se [hacían] el día del Corpus" el 5 de julio de 1629. Los munícipes contaban con «algunas trazas [de custodias] en las casas de la villa" que acordaron revisar y elegir la más conveniente, apremiando a "tratar de concertalla con la brevedad que se pueda». El Concejo volvió a reunirse el 22 de agosto de ese mismo año para expresar que el platero Claudio Genequi había acudido a la localidad desde Zaragoza - «el cual ha traido cartas de abono del Aseo de Zaragoza y del doctor Thomas Secanilla»- para realizar la custodia, según su traza y con un peso de mil onzas ${ }^{8}$.

Los miembros del Ayuntamiento acudieron al notario Francisco de Olit para protocolizar el acuerdo con Genequi al día siguiente -el 23 de agosto-, donde debía obligarse con su mujer Joaquina Alexandre y su hijo Gerónimo en una comanda de veinte mil sueldos a favor del Concejo "para seguridad de todos los cabos" de la capitulación?. Los responsables municipales se comprometieron a abonar catorce mil sueldos al platero por "las hechuras de dicha custodia" -que habría de recibirlos cuando estuviera finalizada-, a proporcionarle casa en la localidad y a concederle la licencia pertinente para cortar madera y suministrarle el "carbon necesario". Por su parte, Genequi se obligó a entregar el ostensorio con seis figuras, una campanilla y «las quatro garras del pie»-todo dorado- para el día del Corpus de 1630; pero probablemente ya había cumplido con su encargo para el mes de febrero siguiente -algunos meses antes del plazo establecido- porque para entonces los jurados de Alcañiz, ante la entrega de la custodia vieja por parte del Cabildo de la colegial, nombraron a unos comisarios para determinar dónde convenía "hazer el sacrario para la custodia nueba" ${ }^{10}$.

En cuanto a la construcción del oratorio dedicado a san Gregorio, el impulso partió del mercader Miguel Valero, que solicitó el permiso pertinente al Concejo el 5 de febrero de $1630^{11}$. Aunque se le concedió ese mismo día, el acuerdo con el capítulo de la colegial no fue protocolizado hasta el 14 de abril de ese mismo año ${ }^{12}$,

7. AHPZ, Pleitos Civiles, J13419-1, pieza 3, ff. 23v.-24r.

8. AHPZ, Pleitos Civiles, J13419-1, pieza 3, f. $24 \mathrm{r}$.

9. El protocolo notarial de Francisco de Olit correspondiente a 1629 no se ha conservado. La copia de la capitulación, en AHPZ, Pleitos Civiles, J13419-3, ff. 24v.-28r. (Alcañiz, 23-VIII-1629), apéndice documental, doc. 1.

10. AHPZ, Pleitos Civiles, J13419-1, pieza 3, f. 28r.-v.

11. AHPZ, Pleitos Civiles, J13419-1, pieza 3, f. 29r.-v.

12. GonZÁlez HeRnándeZ, Vicente. Noticias histórico-artísticas de Alcañiz. Siglos XVII y XVIII. Alcañiz: Centro de Estudios Bajoaragoneses, 1994, pp. 84-86. Una copia del acuerdo en AHPZ, Pleitos 
donde se cedía a Valero el espacio ocupado por «la puerta bulgarmente llamada la puerta de los Novios", y se le permitía colocar un rejado de hierro, realizar «asiento, o, asientos; carnerarios», y disponer "un altar a honrra de Dios Nuestro Señor so la invocacion" que quisiera y sus armas «en cualquier parte della».

Valero volvió a dirigirse al Concejo de la localidad trece días después del acuerdo -el 27 de abril- para expresar que la capilla ya estaba trazada en el suelo, pero que algunos representantes municipales no estaban de acuerdo con el lugar elegido porque era el «encuentro para la puerta principal»" ${ }^{3}$. El Concejo deliberó que la obra podía llevarse a cabo sin excederse «de los ultimos señales que se han hecho ancia la parte de afuera, y señalado con unas picadas», e instó a Valero a que realizase con perfil circular la esquina de la estructura que recaía a la puerta principal ${ }^{14}$. Sin embargo, determinados munícipes no estaban de acuerdo con lo deliberado, porque entendían que las paredes rebasaban el «pilar que [estaba] ancia la puerta principal» ${ }^{15}$.

Las obras del oratorio prosiguieron su curso y, en la reunión del Concejo celebrada el 27 de julio de 1631, los representantes de los habitantes de Alcañiz expresaron que Miguel Valero había «excedido mucho de los señales que por orden del consexo" se habían hecho junto a la "puerta llamada de los Novios»; y que la esquina de la estructura situada "hacia la puerta principal de dicha yglesia" no la había hecho redonda como estaba deliverado. Para remediarlo, los miembros del Ayuntamiento propusieron la construcción de un "portico desde la dicha esquina de la capilla hasta la otra que corresponde al pulpito de San Vicente Ferrer ${ }^{16}$, y notificárselo al propio Valero "que [estaba] en Zaragoza»" Para entonces se había construido «un arco de tan grande ostentacion y hornato para la dicha capilla y yglesia" y tan solo faltaba por realizar su abovedamiento ${ }^{18}$. Por todo ello, los representantes municipales expresaron que ni Miguel Valero ni los «dichos artifices» habían excedido "de las dichas picadas señaladas por el dicho capitol» y, por tanto, no consintieron que se le impidiera a Valero, a los oficiales y "a los artifices» que

Civiles, J13418-3, ff. 181r.-186r.

13. "[...] de hacer una capilla en la puerta de los Nobios de la yglesia colegial de la presente villa, haviendola trazado en el suelo, â algunos parece no ser conveniente y que este de encuentro para la puerta principal. Y que su deseo es hazer dicha obra con gusto y boluntad de este capitulo y consexo [...]» [AHPZ, Pleitos Civiles, J13419-1, pieza 3, ff. 29v.-30r.].

14. AHPZ, Pleitos Civiles, J13419-1, pieza 3, ff. 29v.-30r.

15. AHPZ, Pleitos Civiles, J13419-1, pieza 3, f. 30r.-v.

16. AHPZ, Pleitos Civiles, J13419-1, pieza 3, ff. 30v.-31r.

17. AHPZ, Pleitos Civiles, J13419-1, pieza 3, f. 31r.-v.

18. "Y haviendola traido en el estado y perfeccion que oy esta, que casi está acabada, y perficionada, faltandole solo el cubrilla; haviendose hecho en ella un arco de tan grande ostentacion y hornato para la dicha capilla y yglesia, guardando siempre los dichos artifices el tenor de dicha deliveracion /33r./ y no excediendo de aquella en manera alguna» (AHPZ, Pleitos Civiles, J13419-1, pieza 3, ff. $32 \mathrm{v} .-33 \mathrm{r}$ ) 
la obra no prosiguiera su curso, e instaban a que "no se inove, ni inobar haga ni permita cosa alguna en contrario de la dicha deliveracion ${ }^{19}$.

La fábrica ya debía de estar casi finalizada para el verano de 1633, porque Miguel Valero se ocupó de contratar la realización de trescientos bolones y cuatro pilastras de bronce para una reja -similar a la que cerraba la capilla de Nuestra Señora de los Ángeles del convento de San Francisco de Zaragoza- con Juan Esparbiel -buidador vecino de la ciudad del Ebro-, y del montaje y su posterior colocación en el oratorio con Pablo Escolán, herrero y también vecino de la capital del reino ${ }^{20}$.

\section{LOS PROBLEMAS DEL EDIFICIO A FINALES DEL SEISCIENTOS}

El estado del edificio no debió de preocupar al Cabildo cuando redactó un informe con motivo del sínodo provincial convocado por el arzobispo Juan Cebrián (1644-1662) en Valderrobres (Teruel) en 1656 ${ }^{21}$. Sin embargo, casi dos décadas después -el 9 de febrero de 1673- el Cabildo requirió al albañil Jusepe Soldevilla, al cantero Joan Labastros - «menor de dias»- y al notario Pedro Juan Zapater para realizar una visura a la iglesia porque sufría un problema de goteras y creyeron que podría provocar "grande ruina de caerse" ${ }^{22}$. Soldevilla y Labastros anduvieron por el edificio, y comprobaron que "la mayor parte se llobia por haver muchas goteras" por las que se filtraba gran cantidad de agua, especialmente el altar mayor, "delante de la puerta de la Sacristia mayor", las capillas del Santísimo Sacramento, del Santo Cristo, la Trinidad, Santa Ana, la Virgen de los Dolores, San Bartolomé y la sillería del coro - đde manera que se destruían las sillas del»-, por lo que consideraron que la iglesia corría "evidente peligro de una grande ruina» si no se reparaban las goteras.

Probablemente no debió realizarse ninguna operación para subsanar las filtraciones, porque los munícipes se reunieron para expresar que el edificio continuaba con goteras - la yglesia colegial se llueve»- el 20 de mayo de 1681. Para solucionarlo, propusieron que los jurados, ciudadanos y "oficiales que les parezca" podían acudir al edificio á "hazer visura y reconocer los reparos" necesarios ${ }^{23}$.

19. AHPZ, Pleitos Civiles, J13419-1, pieza 3, f. 33r.-v.

20. Longás lacasa, M. a Ángeles. "Las Artes en Aragón en el siglo XVII según el Archivo de Protocolos Notariales de Zaragoza. De 1631 a 1633”. En BruÑén IbáÑEZ, A. I.; Julve Larraz, L. y Velasco DE la PeÑA, E. (coords.). Las Artes en Aragón en el siglo XVII según el Archivo de Protocolos Notariales de Zaragoza. Zaragoza: Institución "Fernando el Católico», vol. VII, 2006, doc. 7-10111(10975), pp. 348-350; y doc. 7-10112(10976), p. 350, https://ifc.dpz.es/recursos/publicaciones/25/76/_ebook.pdf (fecha de consulta: 16-X-2019).

21. Martín Marco, Jorge y Gil Bordás, José Ángel. "La antigua iglesia colegial...”, op. cit., p. 269, nota 35 .

22. Ibid., nota 36 .

23. AHPZ, Pleitos Civiles, J13419, pieza 3, ff. 42v.-43r. 
Aunque no puede precisarse si se llevó el reconocimiento, algunas de las capillas mencionadas en la visura de 1673 experimentaron reformas poco tiempo después, como la de Santa Ana, cuyo espacio fue aprovechado por Isabel de Ballabriga -baronesa viuda de Letosa- para levantar un nuevo oratorio que contrató en $1682^{24}$. Además, el Concejo otorgó una serie de licencias para construir las capillas de San Antón y de San Pedro Arbués y para renovar la del Santo Cristo y la Virgen de la Soledad -afectada por el problema de goteras de 1673- a finales de esa centuria.

La cofradía de San Antón recibió el permiso para la construcción del oratorio el 23 de mayo de 1694. Debía levantarse en el espacio que estaba «bajo el altar mayor por donde [entraban] los reverendos a decir misa", próximo a la capilla Vespín y a la "columna junto a las sillas donde se [sentaban] los revestidos", para que, de este modo, pudiese permitirles el paso "para entrar y salir» del altar por las «dos columnas" que había junto a la capilla de Pedro Ram de Viu -bajo la advocación de san Mateo-, situada en el lado de la epístola y muy cerca de la cabecera ${ }^{25}$. Aunque en el pleito no se adjuntaron más datos sobre su construcción, probablemente ya debía estar finalizado cuando algunos de los cofrades contrataron el dorado del retablo titular con José Gascón y Francisco Bayod el 3 de mayo de $1701^{26}$. En cuanto a Agapito Andreu - «racionero de la Seo de Zaragoza»-, recibió la licencia para construir su oratorio dedicado a san Pedro Arbués «a la parte del evangelio» del altar mayor -donde estaba situado «el rejado de yerro»- el 10 de abril de $1695^{27}$.

Tres años después -el 10 de agosto de 1698- los munícipes concedieron al canónigo Juan Trullenque la licencia correspondiente para erigir una capilla en el

24. Martín Marco, Jorge y Gil Bordás, José Ángel. "La antigua iglesia colegial...», op. cit., p. 266.

25. «[...] Que por parte de la cofradia de San Anton de la presente ciudad se ha suplicado en consexo sea servido darle licencia para hazer una capilla por su cuenta y gasto en la yglesia colegial de la presente ciudad en el espacio que esta bajo el altar mayor por /50r./ donde entran los reverendos a decir misa, que confronta dicho espacio con la capilla llamada de Vespin, y con la columna junto a las sillas donde se sientan los revestidos: que el consexo acuerde si gusta hazerle la gracia. Deliveran, y dan licencia permiso y facultad a la dicha cofradia del glorioso San Anton para edificar la dicha capilla en el puesto y de la manera que en la propuesta se contiene con tal que haya de dexar paso libre con la anchura y decencia necesaria para entrar y salir los revestidos al altar mayor por entre las dos columnas que hay frontero la capilla de Pedro Ram de Viu, donde de presente estan las sillas de dichos revestigos [...]” [AHPZ, Pleitos Civiles, J13419-1, pieza 3, ff. 49v.-50r.].

26. Thomson Llisterri, Teresa. Las artes en el Bajo Aragón en la primera..., op. cit., doc. 4, pp. 187-189.

27. «[...] Que el doctor Agabito Andreu racionero de la Seo de Zaragoza /50v./ suplica al consexo el permiso y licencia para fabricar una capilla en la yglesia colegial de esta ciudad a la parte del evangelio de la altar mayor, en donde esta el rexado de yerro sola imbocacion de San Pedro Arbues. Que el consexo acuerde si le dará licencia. Deliveraron y dan licencia permiso y facultad al dicho dotor Agavito Andreu para que pueda fabricar una capilla so la imbocacion y lugar contenido en la propuesta» [AHPZ, Pleitos Civiles, J13419-1, pieza 3, f. 50r.-v.]. 
lugar que "de presente [estaba] el Santo Christo y la Virgen de la Soledad» ${ }^{28}$. La primera piedra se colocó el 24 de febrero del año siguiente, y las obras comenzaron según las trazas de Gaspar Serrano inmediatamente después ${ }^{29}$, aunque el estallido de la guerra de Sucesión paralizó los trabajos, que no se retomaron hasta 1717 y prosiguieron hasta su finalización quince años después ${ }^{30}$. El oratorio se construyó en la cabecera del templo medieval, y fue uno de los dos elementos -junto a la torre campanario- que el arzobispo Crespo Agüero permitió conservar, y actualmente se levanta en el tercer tramo del lado de la Epístola del templo barroco [Figs. 1 y 2].

Con todo y con esto, el estado de la colegiata seguía preocupando. El jurado en cap expresó en una reunión del Ayuntamiento -celebrada el 18 de agosto de 1698- que "la columna de la yglesia colegial» situada junto al coro estaba "con gran peligro»-según la opinión de los oficiales-, por lo que se acordó cortar trescientos maderos, cien procedentes de la dehesa de "la Codoñera" y los doscientos restantes en el "vedado" ${ }^{31}$. Sin embargo, otras zonas del templo estaban experimentando algunas actuaciones, como en la capilla Vives -bajo la advocación de la Virgen de los Dolores- ${ }^{32}$, que fue reconocida por mandato del concejo por los canteros Antonio Estrada -que estaba dirigiendo las obras de la torre de la parroquial de Castellote (Teruel), los carmelitas alcañizanos y la iglesia de Gandesa (Tarragona) ${ }^{33}$ - y Vicente Estrada por las filtraciones de agua que tenía el 22 de noviembre de $1699^{34}$.

28. «[...] Que el canonigo Juan Trullenque tiene debocion a fabricar una capilla en la yglesia colegial de esta ciudad, en la que de presente está el Santo Christo, y Virgen de la Soledad, y para ello suplica al consexo se le dé licencia, para ensancharla lo que fuere menester, y que le quede absolutamente el dominio en ella para si, y a los suyos que el consexo lo acuerde. Deliveran y hazen gracia de la sobredicha capilla al dicho canonigo Trullenque para que la pueda fabricar de nuevo, ensanchandose lo que fuere [...]» [AHPZ, Pleitos Civiles, J13419-1, pieza 3, f. 39r.].

29. Hasta el momento, sobre la actividad profesional de Gaspar Serrano en Zaragoza véase Almería, José Antonio et al. Las artes en Zaragoza en el último tercio del siglo XVII (1676-1696). Estudio documental. Zaragoza: Institución «Fernando el Católico», 1983, pp. 179-180.

30. El 20 de noviembre de 1732 se celebró un acto público donde el notario Antonio Benito Arcos protocolizó el relato de la construcción de la capilla (THOMSON LLISTERRI, Teresa. Las artes en el Bajo Aragón en la primera..., op. cit., doc. 32, pp. 305-317).

31. AHPZ, Pleitos Civiles, J13419-1, pieza 3, ff. 40v.-41r.

32. La identificación de esta capilla ya se señala en MARTín MARCO, Jorge y Gil Bordás, José Ángel. "La antigua iglesia colegial...", op. cit., p. 266.

33. Martín MARCO, Jorge. "Aportaciones documentales sobre los maestros de la iglesia de la Asunción de Gandesa (Tarragona) entre 1698 y 1701». Recerca, 2018, 18, 2019, pp. 35-53; MARTíN MARCO, Jorge. "Arquitectura para dos carismas distintos en el Bajo Aragón turolense en el Seiscientos: el convento carmelita de Alcañiz y el descalzo del Desierto de Calanda». Ars Longa, 2019, 28, pp. 91-107.

34. "[...] Que la capilla de Vives de la colegial y a mas se repara no obstante se han llamado a Antonio Estrada y Vicente Estrada, y siempre ba de aumento el lloverse: que el consexo de providencia a lo hacedero $=$ Deliveran que los señores jurados llamen a los dichos Antonio Estrada, y Vicente Estrada, y mediante acto le señalen tiempo fixo para reparar la dicha capilla que no se llueva y lo demas 
3. EL OCASO DEL EDIFICIO MEDIEVAL: EL INCENDIO DEL RETABLO MAYOR Y EL DESPLOME DE LA COLUMNA DEL CORO

El retablo mayor -de finales del siglo XV- sufrió un incendio en octubre de 1731, que obligó a los miembros del Cabildo a destinar "los medios necesarios para hacer el altar maior [...] y para los demas reparos que necesitasse la iglesia” en noviembre de ese mismo año ${ }^{35}$. Este hecho se ha venido señalando como el desencadenante de la ruina de la columna inmediata al $\operatorname{coro}^{36}$, un extremo que nos obliga a descartarlo por cuanto el coro estaba situado a los pies de la nave central y, por tanto, en un punto alejado del altar mayor ${ }^{37}$.

El estado que presentaba la colegial provocó que los canónigos suplicasen al Concejo que tomase una decisión sobre «la composicion y decencia de la colegial respecto de hallarse» con alguna «imperfeccion ${ }^{38}$. Los representantes municipales acordaron poner «en execucion el reparo o construccion de nuebo de la columna de dicha yglesia que [estaba] contigua al coro de ella" y que amenazaba ruina el 19 de agosto de 1733. Para llevarlo a cabo, decidieron poner "carteles llamando a los maestros alarifes que quisieren entender en la referida construccion" y también cubrir y retejar "las bovedas de dicha yglesia -sacando las aguas que se trasmitan en diferentes partes de ella»- si la ciudad contaba con medios disponibles.

El incendio del retablo, el mal estado de la columna «inmediâta al coro» y los problemas de filtraciones de aguas que padecía la iglesia fueron los motivos por los que el Cabildo nombró a Matías Siesso, Josef Cebrián, Félix Monreal y Antonio Vélez para que «tratasen la direccion, y medios conducentes, para la maior grandeza del Señor y decencia del altar e iglesia»-junto a los regidores nombrados por el Ayuntamiento- el 21 de agosto de $1733^{39}$. Pero tras no haber podido lograr su cometido, se creó una nueva junta de fábrica para decidir si resultaba conveniente reparar el edificio o construir uno nuevo ${ }^{40}$. El Concejo volvió a reunirse el 5 de septiembre, y entre las propuestas realizadas por el caballero regidor se encontraba la del nombramiento de una serie de personas «â cuyo cargo ha de correr la

que les tocare por obligacion en considerazion se obligaron a ello y percivieron mil y cien sueldos jaqueses [...]” [AHPZ, Pleitos Civiles, J13419-1, pieza 3, f. 59v.-60r.].

35. IBÁÑEZ FERNÁNDEZ, Javier y MARTín MARCO, Jorge. "El antiguo retablo mayor...», op. cit. (en prensa).

36. Thomson Llisterri, Teresa. Las artes en el Bajo Aragón en la primera...”, op. cit., p. 46; y de la misma autora, Iglesia..., op. cit., p. 49.

37. MARTín Marco, Jorge y Gil Bordás, José Ángel. «La antigua iglesia colegial..., op. cit., p. 269.

38. AHPZ, Pleitos Civiles, J13419-1, pieza 3, ff. 44r.-45r.

39. Archivo Parroquial de Alcañiz [APA], Libro de Determinaciones del Cabildo, vol. 1, f. 91v. (Alcañiz, 2-V-1733). También en IBÁÑEz FERnÁNDEZ, Javier y MarTín Marco, Jorge. «El antiguo retablo mayor...", op. cit. (en prensa).

40. APA, Libro de Determinaciones del Cabildo, vol. 1, f. 93r.-v. (Alcañiz, 21-VIII-1733). Documento referenciado en IBÁÑEZ FERNÁNDEZ, Javier y MARTín MARCO, Jorge. "El antiguo retablo mayor...", op. cit. (en prensa). 
direccion de la composicion, ô nueba construccion de la columna», y eligieron a Pablo Balaguer, Juan de Santa Pau, Antonio Serra y Francisco Tamarit, que debían destinar parte del dinero procedente del caudal de las primicias ${ }^{41}$.

Finalmente, la reparación de la columna se contrató con Miguel de Aguas el 14 de noviembre de 1733. El acuerdo obligaba a Aguas a derribarla y erigirla posteriormente con "piedra labrada uniforme y correspondiente con su vasa y capitel», desde el pavimento hasta el arranque de los arcos, y "apuntalar y asegurar» los arcos y las bóvedas correspondientes a los tramos adyacentes; todo ello por novecientas libras provenientes de las primicias y en un plazo de tres meses ${ }^{42}$. Esta operación -sumamente arriesgada- no consiguió su objetivo, y la estructura continuaba preocupando al Cabildo, que se reunió para nombrar a cuatro miembros -Franco Escuín, Matías Siesso, Josef Falbre y Tomás Zapater- para la «direccion de los reparos" necesarios de la colegial -especialmente la "seguridad del coro»-, y cederles "toda accion" para aprobar cualquier disposición en la junta de fábrica el primero de agosto de $1735^{43}$. Sin embargo, el Cabildo volvió a congregarse cuatro días después, y de nuevo el deán informó que se había «undido, y asolado la columna contigua al coro" y con ella, "dos porciones de naves considerables entre tres, y quatro de la mañana del dia dos de agosto" ${ }^{44}$, por lo que "dicha ruina pedia mayor inspeccion" que lo realizado hasta el momento, así que confirió poderes a los representantes del Cabildo en la junta de fábrica para "quanto se ofreciere aunque sea para fabrica de iglesia nueba ${ }^{45}$.

\section{LA MEMORIA DEL EDIFICIO MEDIEVAl a TRAVÉS DE LAS DEClARACIONES DE LOS TESTIGOS}

La mayoría de los testigos aportados por el Ayuntamiento en la causa del escudo de armas eran profesionales de la construcción vinculados con la demolición del templo medieval y con las obras del nuevo. Aunque algunas declaraciones variaban ligeramente, todos recordaban haber visto los escudos de la ciudad "por los costados y caveza” del antiguo retablo, sobre la puerta de la sala capitular

41. AHPZ, Pleitos Civiles, J13419-1, pieza 3, ff. 45v.-46r.

42. Archivo Histórico de Protocolos de Alcañiz [AHPA], Pablo Alberto Suñer, 1733, ff. 219r.-220v. (Alcañiz, 14-XI-1733), apéndice documental, doc. 2. El Ayuntamiento aprobó el acuerdo catorce días después (AHPZ, Pleitos Civiles, J13419-1, pieza 3, ff. 46v.-47r.).

43. AHPZ, Pleitos Civiles, J13418-1, pieza 3, f. 164r.-v.

44. «[... haviendosse hundido, y assolado la columna contigua al coro, y con ella dos porciones de naves considerables entre tres, y quatro de la mañana del dia dos de agosto del susso dicho año, y que dicha ruina pedia maior inspeccion, que los reparos [...]” [APA, Libro de Determinaciones del Cabildo, vol. 1, f. 103r.-v. (Alcañiz, 5-VIII-1735)]. Documento referenciado en IBÁÑEZ FERNÁNDEZ, Javier y MARTín MARCO, Jorge. «El antiguo retablo mayor...», op. cit. (en prensa). Otra interpretación del documento en Thomson Llisterri, Teresa. Iglesia..., op. cit., p. 50.

45. AHPZ, Pleitos Civiles, J13418-3, pieza 2, f. 165r. 
- "que ha sido y es cuerpo primero de la torre de las campanas»-, en los frisos de las columnas, en las claves de las bóvedas, en la capilla del Espíritu Santo -"que existía en el attrio antiguo de la puerta principal»- y en "otras partes» de la iglesia.

Crespín Gascón expuso que había trabajado en la antigua colegial realizando reparos o "limpiando todos los años la misma yglesia» junto a su padre José -que había sido «albañil de la ciudad»-. También había acudido a sofocar el incendio del retablo mayor, había trabajado en la demolición del edificio gótico y en la construcción del nuevo; y recordaba los escudos dispuestos sobre la puerta de la sala capitular -que desapareció tras "haverse escarpado" la pared para "igualar con la nueba obra"-; y en el acceso al campanario, que también se canceló "por haverse mudado dicha puerta por causa de la citada nueba obra ${ }^{46}$.

Antonio Picaso -maestro albañil de 56 años- comenzó su declaración expresando que había aprendido su oficio en la cuadrilla de su tío Antonio Gascón -hermano de Crespín- y que lo ejercía desde hacía 40 años. Había trabajado en la antigua colegial realizando algunas reparaciones, sofocando el incendio del retablo, en su demolición y en la construcción de la nueva iglesia posteriormente. Recordaba haber visto los escudos de la ciudad en los mismos lugares que el testigo anterior, "en las quatro pechinas de la media naranja que desizo" durante la demolición -probablemente de alguna de las capillas del Seiscientos- y sobre el acceso a la torre, situado en el interior del templo ${ }^{47}$.

El albañil Sebastián Alloza -de la misma edad que el testigo anterior y natural de Cañizar del Olivar (Teruel) - conoció los rudimentos de su oficio en la cuadrilla de Crespín Gascón, y juntos asistieron «en seguida a la demolicion de la anttigua yglesia colegial». Alloza también recordaba haber visto durante los trabajos «uno, o mas leones de los que havia al rafe de los texados de dicha yglesia para arrojar el agua quando llovia» con las armas de Alcañiz - una caña con las barras encima» ${ }^{48}$.

A estas declaraciones les siguieron las de los canteros Juan de Bengoechea y Agustín Alegría. El primero expresó que era natural de "Zizurgui -Zizúrkil- en la provincia de Guipuzcoa», que tenía 63 años, y era vecino de Alcañiz desde hacía treinta y nueve. Reconoció haber realizado una "pila de labatorio para la sacristia" de la capilla del Santo Cristo atendiendo a las órdenes de la junta de fábrica, para lo cual tuvo que quitar otra preexistente, donde comprobó que había una caña grabada; y que por orden del Ayuntamiento realizó «una piramide en el cabo y por remate del puente» de entrada a la ciudad, donde cinceló una caña ${ }^{49}$.

El segundo -que era dos años mayor que Bengoechea y natural de la ciudad- declaró haber sido monaguillo en la colegial, y que "fabrico y laboreo» junto

46. AHPZ, Pleitos Civiles, J13418-3, pieza 2, ff. 91r.-117r. (Alcañiz, 12-IV-1775).

47. AHPZ, Pleitos Civiles, J13418-3, pieza 2, ff. 117r.-142v. (Alcañiz, 12-IV-1775).

48. AHPZ, Pleitos Civiles, J13418-3, pieza 2, ff. 147v.-151r. (Alcañiz, 15-IV-1775).

49. AHPZ, Pleitos Civiles, J13419-1, pieza 3, ff. 151r.-153r. (Alcañiz, 15-IV-1775). 
a su padre -Gerónimo Alegría, "maestro cantero"- un arca de piedra para el agua del lavatorio de la sacristía de Santa María la Mayor por orden del Ayuntamiento, donde grabó una caña "sobre la jetta» y entre las palabras de Jesús y María. Alegría recordaba que cuando estaba "destinado con su padre al oficio de canttero" se levantó una columna en la antigua iglesia, aunque no pudo especificar si fue en 1733 o $1734^{50}$.

Otros testigos que no pertenecían al oficio de la construcción también declararon, como Antonio Duranza -natural de la ciudad, de 59 años-, quien recordaba que en el exterior de la antigua colegial no había escudos de Alcañiz, y que en el acceso principal «solo se advertia colocada la imagen de Nuestra Señora en pie que denotava el misterio de la Asumpcion, con dos estatuas en figura de angeles, â los lados» ${ }^{51}$.

\section{LOS INICIOS DE LA CONSTRUCCIÓN DE LA NUEVA COLEGIAL}

Tomás Crespo de Agüero -arzobispo de Zaragoza entre 1727 y 1742- firmó el decreto por el cual autorizaba la demolición del arruinado templo medieval y la conservación tanto de la torre campanario como de la recién concluida capilla del Santo Cristo y la Virgen de la Soledad, el 20 de agosto de $1735^{52}$. El prelado también permitió destinar todo el importe de las primicias y concedió cuarenta días de indulgencia a quienes concurriesen con limosnas a la fábrica de la iglesia.

El proyecto para la nueva colegial ya estaba listo para los primeros días de enero de 1736. Para entonces, el Cabildo de Santa María la Mayor se congregó para informar al resto de componentes que sus representantes en la junta de fábrica -compuesta también por los del Ayuntamiento- habían "Combenido y ajustado" las obras, algo que el Cabildo en pleno aprobó y les agradeció sus gestiones ${ }^{53}$. Tres meses después -el 4 de abril- el deán de la colegial propuso «ensanchar la nabe principal del futuro templo de 54 palmos, a 56", y expresó la necesidad que la junta tenía de cargarse un censal de cuatrocientas libras, por lo que solicitaba el producto del legado del "cimborrio a fin de luir cada un año 60 libras del principal de dicho censo", destinar otras setenta del "legado de Palao", y que el arzobispo Crespo Agüero acabó autorizando ${ }^{54}$.

El acuerdo para la construcción de la nueva colegial se protocolizó ante el notario Miguel José de la Figuera el 8 de abril de 1736, donde los maestros Miguel

50. AHPZ, Pleitos Civiles, J13419-1, pieza 3, ff. 153r.-177r. (Alcañiz, 15-IV-1775).

51. AHPZ, Pleitos Civiles, J13418-1, pieza 2, ff. 88v.-89r. (Alcañiz, 8-IV-1775).

52. Magdalena lacambra, Federico. La iglesia colegiata de Alcañiz. Apuntes históricos. Zaragoza: El Noticiero, 1944, p. 14. El autor pudo consultar los libros de fábrica de la colegial antes de su desaparición en el transcurso de la Guerra Civil.

53. Se congregó el día 6 de enero de 1736 (AHPZ, Pleitos Civiles, J13418-1, pieza 1, f. 165r.).

54. AHPZ, Pleitos Civiles, J13418-1, pieza 1, f. 165v.-166r. 
de Aguas y Silvestre Colás aceptaron realizar la obra según la traza y las condiciones redactadas por Domingo de Yarza, por treinta y cuatro mil libras jaquesas en un plazo de diez años ${ }^{55}$. La primera piedra se colocó el 20 de mayo de ese mismo año ${ }^{56}$, y Miguel de Aguas encargó su labra a Crespín Gascón -«maestro arbañil natural y vecino de la presente ciudad»-, tal y como relató en su declaración en el pleito $^{57}$. Gascón realizó un agujero para colocar un baso con monedas y escrituras, y grabó una caña -las armas de la ciudad- en uno de los frentes de la piedra posteriormente. Acto seguido "hizo conducir dicha piedra" a la colegial, donde después de ser bendecida por el arzobispo Crespo Agüero y realizar las ceremonias «acostumbradas» en presencia del Ayuntamiento, del Cabildo y "otras distintas personas»; la colocó «su ilustrisima» y Gascón la ocultó «en una peña y nicho que se hizo en ella para tal fin".

Antonio Picaso declaró que la piedra tenía la forma «de un quartal de medir grano", con un "abugero" en el medio y un tape para colocar un vaso de vidrio, y confirmó que Crespín había grabado una caña en «un costado». El testigo la condujo hasta la sala capitular de la colegial, y una vez allí, "fue sacada a la puerta de dicha yglesia poniendola sobre una mesa con un arco de ramos", y que, tras realizar las ceremonias, se colocó «en el primer machon de la capilla que llaman de Ram ${ }^{58}$. Además, el testimonio del albañil Sebastián Alloza -aprendiz de Crespín "al tiempo de dar principio a la obra del nuebo templo»- coincidió con lo declarado por Picaso ${ }^{59}$.

Los trabajos se encontraron con problemas muy pronto, en 1737. Por este motivo, el Concejo se reunió el 17 de junio de ese año para expresar que se había "experimentado mucha tivieza en la fabrica", debido -fundamentalmente- a "la desidia de los maestros", que habían "quitado palmo y medio del grueso que deven tener [los muros] segun lo capitulado", tal y como habían expresado maestros peritos -cuyas identidades no se precisan- en una declaración. De este modo, decidieron crear una nueva junta de fábrica, cancelar el acuerdo con Miguel de Aguas y Silvestre Colás, tasar el trabajo realizado hasta el momento y abonar a

55. El documento fue publicado en ThOmSOn Llisterri, Teresa. Las artes en el Bajo Aragón en la primera..., op. cit., doc. 34, pp. 325-337.

56. Magdalena Lacambra, Federico. La iglesia colegiata..., op. cit., pp. 21-24; el documento fue publicado, con una transcripción que no compartimos, en GonZÁLEZ HernáNDEZ, Vicente. Noticias bistórico-artísticas..., op. cit., pp. 103-106; y transcrito correctamente en THOMSON LlISTERRI, Teresa. Las artes en el Bajo Aragón en la primera..., op. cit., doc. 35, pp. 339-346.

57. AHPZ, Pleitos Civiles, J13419-1, pieza 3, ff. 97v.-98r. (Alcañiz, 12-IV-1775).

58. AHPZ, Pleitos Civiles, J13419-1, pieza 3, ff. 117r.-142v. (Alcañiz, 12-IV-1775).

59. AHPZ, Pleitos Civiles, J13419-1, pieza 3, ff. 147v.-151r. (Alcañiz, 15-IV-1775) 
ambos el dinero correspondiente ${ }^{60}$, aunque el acuerdo no se rescindió hasta el mes siguiente ${ }^{61}$.

El Cabildo volvió a congregarse el 4 de enero de 1738, donde el deán expresó «que la fabrica de la nueba yglesia se [hallaba] suspendida» desde la rescisión del contrato con los maestros, y que creía conveniente que los trabajos debían continuar por administración y al cargo de un solo maestro "para evitar los incombenientes, y desazones que hasta ahora se [habían] experimentado». Ante esto, se acordó crear una nueva junta de fábrica, y tras la designación por parte del Ayuntamiento de sus representantes, el Cabildo hizo lo propio con los suyos ${ }^{62}$.

Silvestre Colás acabó apartándose de la obra el 27 de diciembre de $1738^{63}$ y, por este motivo, la junta de fábrica nombró tasador de los trabajos a Domingo de Yarza el 29 de enero del año siguiente, para que valorase, junto a José Francín, la obra realizada por Colás en la colegial ${ }^{64}$. Yarza y Francín aceptaron el nombramiento el 2 de febrero, y emitieron su parecer cinco días después ${ }^{65}$. Los trabajos continuaron por administración al cargo de Miguel de Aguas en solitario, y la situación comenzó a remontar a partir de entonces, porque «los machones y paredes del templo» se fueron levantando entre 1739 y 1741, y el suministro de madera - procedente de las localidades turolenses de La Zoma o Villarluengo- se contrató entre 1741 y $1742^{66}$; un ritmo que se mantuvo hasta el ecuador de la centuria [Figs. 3 y 4$]^{67}$.

\section{Fray Atanasio AZNAR EN LA COlegial}

La figura de este religioso franciscano todavía cuenta con algunos interrogantes acerca de su origen, formación y trayectoria previa a su llegada a Alcañiz para hacerse cargo de la construcción de la nueva iglesia de su orden en torno a 1738. Para entonces, los frailes menores se dirigieron al Ayuntamiento de la ciudad mediante una misiva solicitando permiso para construir una nueva iglesia en un solar más grande a comienzos de ese año. En ella expresaron que las obras

60. AHPZ, Pleitos Civiles, J13419-1, pieza 3, ff. 50v.-52v. El original fue publicado en ABós CASTel, M. ${ }^{a}$ Pilar y Micolau Adell, José Ignacio. "Documentos...", op. cit., pp. 98-99.

61. La noticia ya se da en Magdalena Lacambra, Federico. La iglesia colegiata..., op. cit., p. 25. El documento se publicó en THOMSOn LuIsTerri, Teresa. Las artes en el Bajo Aragón en la primera..., op. cit., doc. 38, pp. 359-362.

62. AHPZ, Pleitos Civiles, J13418-3, pieza 1, ff. 166r.-167r.

63. Thomson Llisterri, Teresa. Las artes en el Bajo Aragón en la primera..., op. cit., doc. 39, pp. 365-366.

64. Ibid., doc. 40, pp. 369-370.

65. Ibid., doc 41, p. 373, y doc. 42, pp. 375-376.

66. Magdalena lacambra, Federico. La iglesia colegiata..., op. cit., pp. 47-51; ThOmson LlisteRRI, Teresa. Las artes en el Bajo Aragón en la primera..., op. cit., doc. 43, pp. 379-381.

67. El seguimiento de los trabajos, en Magdalena LaCAmbra, Federico. La iglesia colegiata..., op. cit., pp. 62-72. 
habrían de estar dirigidas por un «arquitecto de la de singular suficiencia orden»sin duda, fray Atanasio-, "el que si gusta vuestra señoria y pareciere bien a la Junta de Fabrica, gobernara la Fabrica nueva de Santa Maria graciosamente», e incluso se comprometieron a no crear inconvenientes a la fábrica de la colegial mientras durase la de los franciscanos ${ }^{68}$. El Concejo autorizó la construcción a finales de febrero, y ambas partes firmaron una concordia para evitar malas relaciones, en la que -entre otras cosas- el director de las obras de los franciscanos debía convertirse en "socio del de la colegial y que éste recíprocamente correspondiera en la direccion de aquélla» [Figs. 5 y 6$]^{69}$.

Iniciadas ya las obras de los franciscanos ${ }^{70}$, las primeras intervenciones del religioso en Santa María la Mayor fueron en calidad de maestro nombrado para emitir su parecer en determinadas cuestiones constructivas que iban surgiendo durante los últimos años de la maestría de Miguel de Aguas, que debía tener de ayudante a José Maurat. La primera vez que acudió el franciscano a Santa María la Mayor fue en diciembre de 1746. Para entonces, se estaba discutiendo el correcto acoplamiento de la torre campanario medieval y la elevación del cimborrio, y para ello se requirieron los servicios del maestro de obras Onofre Gracián -que acudió desde Zaragoza- para que emitiera su parecer sobre el informe que habían realizado José Francín -de Caspe- y Miguel de Aguas acerca del modo de realizar esas obras. A esta discusión se unió fray Atanasio, que, junto a Gracián, propusieron otra forma de llevarlas a cabo que finalmente fue la aceptada ${ }^{71}$.

Tres años después -el 22 de junio de 1749- volvieron a surgir problemas en las obras de la colegial. En este caso, la junta de fábrica dudaba si el «arco de punto del tímpano de la torre estaba o no bajo» y, si realmente lo estaba, debía evitarse que los tirantes cargasen sobre las bóvedas de los arcos, por lo que acordaron llamar a José Francín para que, "en vista de lo arduo del caso», lo estudiase junto a fray Atanasio y José Maurat, y que los tres aprovechasen la oportunidad para examinar "los ochavos en los que cargaban los tirantes de la linterna de la media naranja del Santo Cristo". Maurat y Francín emitieron diferentes informes que entregaron por escrito a la junta el 29 y el 31 de julio de ese año, pero, para explicar mejor su opinión, el primero de ellos realizó un modelo de madera que fue examinado por el franciscano, quien emitió otro parecer que acabó siendo aceptado por la junta ${ }^{72}$.

68. El documento fue desglosado, sin indicar la fuente, en ibidem, p. 31. El original, en Archivo Municipal de Alcañiz [AMAl], Libro de Acuerdos del Ayuntamiento, 1736-1740, s/f (Alcañiz, 31-I-1738).

69. Magdalena Lacambra, Federico. La iglesia colegiata..., op. cit., p. 32.

70. La demolición de la iglesia del Quinientos ya se había producido en 1740 (MARTín MARCO, Jorge. "La circulación de maestros franceses entre las diócesis de Zaragoza y Tortosa durante los siglos XVI y XVII. El caso de Pedro Pizarro». Archivo de Arte Valenciano, 2018, XCIX, pp. 87-109, espec. p. 102, nota 75).

71. Magdalena lacambra, Federico. La iglesia colegiata..., op. cit., pp. 66-68.

72. Ibid. 
Maurat quedó al frente de las obras tras el fallecimiento de Miguel de Aguas en 1749, pero acabó apartándose de la dirección al año siguiente para hacerse cargo de la construcción del retablo mayor y el de San Juan Bautista de la iglesia parroquial de Torrecilla de Alcañiz (Teruel) ${ }^{73}$. La junta de fábrica nombró director de las obras de la colegial a fray Atanasio Aznar -y no Anastasio como se ha venido transcribiendo ${ }^{74}$, momento en el que también le solicitaron su parecer sobre si la construcción de algunas partes de la iglesia podía realizarse con piedra y no con ladrillo, tal y como estaba estipulado en el acuerdo de $1736^{75}$.

Las obras continuaban su curso, pero el Cabildo se congregó y expresó que para «tener la mayor seguridad de la fabrica de la yglesia por la direccion que lleba el padre Atanasio», encargó a los canónigos Sieso y Cebrián que propusiesen en la junta si creían "conveniente mandar hazer una visura» el 19 de mayo de $1752^{76}$. En cualquier caso, el ritmo de los trabajos debió de descender, o incluso paralizarse, porque la junta se reunió el 12 de abril de 1755, para expresar que ya era «tiempo proporcionado para empezar a trabaxar en la fabrica» de la colegial, y, para el adelantamiento de esta, era necesario nombrar "director [...] asistente diario", y acordaron volver a designar a fray Atanasio, que habría de percibir «cien pesos de a ocho reales de plata en cada un año por su asistencia, y direccion» ${ }^{77}$. Para entonces, el franciscano estaba encargándose de la realización de las trazas para la iglesia parroquial de Munébrega (Zaragoza) ${ }^{78}$ y las de la torre -que finalmente no se eligieron- de la iglesia de Calaceite, localidad situada en la actual provincia de Teruel y perteneciente a la diócesis de Tortosa por aquel entonces ${ }^{79}$.

73. Ibid., p. 67. El acuerdo fue publicado en ThOmson LlisterRi, Teresa. Las artes en el Bajo Aragón en la primera..., op. cit., doc. 49, pp. 403-409. A la postura de los retablos de Torrecilla concurrieron también los escultores Juan Antonio Martín, Bernabé Mendoza y Joseph Ochando, vecinos de Belmonte de San José, Calanda y Morella respectivamente.

74. Así se transcribió en Magdalena lacambra, Federico. La iglesia colegiata..., op. cit., pp. 66-68; y acabó asumiéndose en THOMSON LLISTERRI, Teresa. Las artes en el Bajo Aragón en la primera..., op. cit., p. 52; y en Iglesia..., op. cit., p. 50.

75. Magdalena Lacambra, Federico. La iglesia colegiata..., op. cit., p. 67.

76. El documento aparece referenciado en MARTín MARCO, Jorge. "Aportaciones documentales...", op. cit., p. 38, nota 11.

77. «[...] propuso el señor canonigo don Josef Cebrian que en atencion a ser tiempo proporcionado para empezar a trabaxar en la fabrica de la insigne iglesia colegial y para el adelantamiento de esta que era precisa se determinara dia para dicho fin, y que se nombrase director de dicha fabrica asistente diario para el cuidado de ella y asimismo oficiales, y peones para operar; determinaron dichos señores y nombraron en director de dicha fabrica al padre Atanasio Aznar religioso francisco, y maestro de obras, con cien pesos de a ocho reales de planta en cada un año por su asistencia, y direccion cuya resolucion está firmada del secretario de la junta Andres Magallon [...]» [AHPZ, Pleitos Civiles, J13418-3, pieza 1, f. 159r.-v.].

78. Llaguno y Amírola, Eugenio. Noticias de los arquitectos y arquitectura de España desde su restauración. Madrid: Turner, 1977, vol. IV, p. 276.

79. Vidiella y JasÁ, Santiago. Recitaciones de la historia política y eclesiástica de Calaceite. Calaceite: Ayuntamiento de Calaceite, Familia Jassá, 1996, p. 351. 
Atanasio alcanzó la cúspide de su carrera en febrero de 1758, cuando fue nombrado académico de mérito por la Academia de San Fernando ${ }^{80}$. El religioso presentó el corte transversal y la planta de la iglesia de la orden en Alcañiz ${ }^{81}$, un edificio de tres naves a la misma altura, con transepto retrasado y cimborrio a punta de diamante -con un elevado tambor- en la encrucijada y cabecera ochavada. La sección muestra una de las dos torres que debían flanquear la fachada, rematada con un chapitel bulboso -como el ideado por Contini para la torre de la catedral del Salvador de Zaragoza- ${ }^{82}$ que evocaba a los de Santa María la Mayor, y que finalmente no se aplicó en la iglesia [Figs. 7 y 8].

Ejerciendo ya su cargo, fue requerido para emitir su parecer acerca del estado en el que se encontraba la iglesia parroquial de Estadilla (Huesca) en $1759^{83}$; y entregó los diseños para la ermita de Santa Bárbara de Maella (Zaragoza) ${ }^{84}$; los de la parroquial de Cañizar del Olivar (Teruel) ${ }^{85}$, y los de la iglesia de Batea - «las tres portadas y el timpano y pilastras nuevas para dicho frontis» ${ }^{86}$ y el convento franciscano de Jesús en Tortosa ${ }^{87}$, dos localidades situadas en la provincia de Tarragona.

80. Fernández Agudo, María Pilar y SÁnchez de León Fernández, María Ángeles. «Índice de cargos académicos de la Real Academia de Bellas Artes de San Fernando en el siglo XVIII». Academia, 1988, 67, pp. 371-458, espec. p. 390.

81. Los diseños fueron publicados en SAMBricio, Carlos. La arquitectura española de la Ilustración. Madrid: Consejo Superior de los Colegios de Arquitectos de España, 1986, p. 38; y en ArBAIZA BlanCO-SOlER, Silvia y Heras CASAS, Carmen. "Inventario de los dibujos de arquitectura (de los siglos XVIII y XIX) en el museo de la Real Academia de Bellas Artes de San Fernando (V)". Academia, 2004, 98-99, pp. 121-262, espec. pp. 124-125.

82. IBÁÑEZ FERNÁNDEZ, Javier y SuTERA, Domenica. «Entre Gaspar Serrano y Giovanni Battista Contini: la reforma barroca del campanario de la catedral de Zaragoza». Anuario del Departamento de Historia y Teoría del Arte, 2010, XXII, pp. 189-208. Este modelo tuvo una gran fortuna en Aragón a lo largo de la centuria [MARTín MARCO, Jorge. "La formación de los profesionales de la construcción en la Zaragoza del Barroco: los exámenes del pleito de Manuel Casanova y Francisco López contra el gremio de albañiles (1764-1767)». Artigrama, 2018, 33, pp. 257-298, espec. pp. 287-288].

83. PuIG SANCHIS, Isidro. "Los Burria. Maestros alarifes aragoneses en la Lleida del siglo XVIII". Boletín del Museo e Instituto Camón Aznar, 2004, 94, pp. 329-278, espec. doc. IV, pp. 357-359.

84. Cortés Borroy, Francisco Javier. «El Barroco en la Comarca del Bajo Aragón Caspe: algunos documentos inéditos conservados en el Archivo de Protocolos Notariales de Caspe». Cuadernos de Estudios Caspolinos, 2009, 28, pp. 223-258, espec. pp. 247-251.

85. Simón Moreno traspasó las obras a Miguel Cólera el 8 de agosto de 1779, que debía continuar los trabajos «con arreglo a la traza que se le entrega de frai Atanasio Aznar» (THOMSON LLISTERRI, Teresa. Las artes en el Bajo Aragón en la segunda mitad del siglo XVIII. Estudio documental. Alcañiz: Centro de Estudios Bajoaragoneses, 2002, doc. 40, pp. 363-364; y doc. 41, pp. 367-370).

86. Alanyá, Josep. "Església de Batea (Bisbat de Tortosa. Prov. de Tarragona). Contracte de construcción". Boletín de la Sociedad Castellonense de Cultura, 2006, 82, pp. 323-340, espec. p. 333.

87. Muñoz SEBASTiá, Joan Hilari. La construcció del convent franciscà de Jesús (1732-1792). Els fonaments d'un poble. Tortosa: EMD de Jesús, 2014, p. 13. 


\section{El ENFRENTAMIENTO ENTRE EL AYUNTAMIENTO Y EL CABILDO POR LA COLOCACIÓN DEL ESCUDO DE LAS ARMAS DE LA CIUDAD}

Para la construcción de la nueva iglesia colegial se conformó una junta de fábrica en la que estaban representados los miembros del Cabildo y el Ayuntamiento. Sin embargo, ambas instituciones mantenían unas malas relaciones que provocaron que los primeros interpusieran un pleito contra el Ayuntamiento en $1758^{88}$, y otro en 1771 por la pretensión de colocar el escudo de armas de la localidad en el templo, porque los munícipes entendían que estaban en su derecho al haber destinado el caudal de las primicias para las obras [Fig. 9].

La disputa ya había surgido el 23 de julio de 1771. Ese día se congregó el Cabildo en la sala capitular, donde el deán expresó que la junta de fábrica quería colocar las armas en el acceso principal del templo, y por ello se "comisionó" al canónigo Tamarit para hacerles llegar que no estaban de acuerdo con esa pretensión y que no dudarían en emprender acciones legales si la otra parte persistía ${ }^{89}$.

Los miembros del Cabildo cumplieron su amenaza y, una vez incoada la causa, se reunieron el 12 de junio de 1773 para expresar la buena voluntad que tenía el Ayuntamiento para resolver el asunto del escudo ${ }^{90}$. Poco tiempo después -el 2 de julio- los de Santa María permitieron al Ayuntamiento la colocación del escudo de armas en el acceso principal -«unas sobre otras perpendicularmente»-, pero con la condición de "que no las ponga en otra parte de la yglesia, ni en sus ornamentos»" ${ }^{91}$. Una semana después, el Cabildo expresó que continuaba adelante con el pleito porque la ciudad no cedía en su pretensión ${ }^{92}$.

Ambas partes reunieron pruebas -tanto orales como documentales- para demostrar su implicación económica en la construcción y manutención, tanto del viejo templo medieval como del nuevo. Los testigos aportados por el Cabildo expresaban que «han sido y son dueños, señores y verdaderos posehedores de la referida iglesia colegial de Santa Maria ${ }^{93}$, y que sin su permiso no podían colocarse escudos de armas ni por el exterior ni en los altares. También declararon que el Cabildo tenia "fabrica en la propia yglesia, para su ampliacion, corriendo toda ella, al cuidado, providencias y ordenes del mismo cavilo, ajustando y pagando por si, lo que ha sido preciso para todo". Además, los miembros del Cabildo aportaron asientos de los libros de decretos en los que demostraba su implicación en las obras del nuevo templo.

88. AHPZ, Pleitos Civiles, J13414-4

89. AHPZ, Pleitos Civiles, J13418-3, pieza 1, f. 167r.-v.

90. AHPZ, Pleitos Civiles, J13418-3, pieza 1, ff. 167v.-168r.

91. AHPZ, Pleitos Civiles, J13418-3, pieza 1, f. 168r.-v. El original se publicó en ThOMson LLISTERRI, Teresa. Iglesia..., op. cit., p. 75.

92. AHPZ, Pleitos Civiles, J13418-3, pieza 1, f. 169r.-v.

93. AHPZ, Pleitos Civiles, J13418-3, pieza 1, ff. 5r.-18r. (declaración de Pedro Fraga), ff. 18r.-31r. (declaración de Miguel Gargallo, maestro tafetanero, de Alcorisa), ff. 31r.-43r. (declaración de Antonio López, soguero), fechadas el 14-XII-1771; ff. 43v.-60r. (declaración de Antonio Ballester), ff. 60r.-75r. (declaración de Baltasar Ribera), fechadas el 14-I-1772. 
El Ayuntamiento de Alcañiz entendía que debía colocar sus armas en el edificio y en el mobiliario litúrgico porque había contribuido en la manutención de la colegial con el caudal procedente de las primicias desde hacía siglos. Para demostrar que el Concejo había colocado el escudo de armas en otras empresas arquitectónicas -y artísticas- que habían sido sufragadas por la institución, dos munícipes, acompañados del escribano de la causa, realizaron un recorrido por diferentes puntos de la ciudad el 3 de abril de $1775^{94}$. En el periplo -que constituye un perfecto retrato del Alcañiz finisecular- se mencionan edificios que han llegado a nuestros días -la casa consistorial o la lonja- y otros que no corrieron la misma suerte, como el cuartel; el ferial; el «matadero, pescateria y ornos de cocer pan llamados nuevo y de consexon; los portales del Puente y de las Monjas, o el convento de dominicas de San Gregorio, construido a finales del Quinientos y demolido por las autoridades locales tras los daños sufridos durante la guerra de la Independencia ${ }^{95}$. Sin embargo, el Cabildo requirió a Joseph Forniés -receptor del pleito- para que realizase una "inspeccion ocular" al templo, donde enumeró los lugares donde aparecían los escudos de la ciudad y del Cabildo ${ }^{96}$.

Además, los canónigos Josef Gre y Joaquín Egea solicitaron «el diseño, o diseños, y planta, o plan» realizado para la construcción del nuevo templo, y el escribano receptor de la causa requirió a Joaquín Faci y Pantaleón Arcayne para que los presentaran. Ambos mostraron «la planta, o plan de la iglesia y tres diseños parciales de la fachada" e indicaron que "todos se siguen en parte variando alguna cosa", aunque en uno de ellos se notaba "en el portico sobre el primero cuerpo, y en el remate de él dos nichos, o targetas cortadas, ó raspadas cubiertas con papel blanco sin advertirse armas algunas» ${ }^{97}$. Con esta petición, el Cabildo quería asegurar que no se había previsto la colocación del escudo de armas en la fachada de la colegial.

94. AHPZ, Pleitos Civiles, J13419-1, pieza 3, ff. 8r.-14r. (Alcañiz, 3-IV-1775), apéndice documental, doc. 3 .

95. "[...] pase en su compañía al portal de la dicha ciudad que se intitula de las monjas. Y en la parte superior de dicho portal señalaron, y se encuentra un escudo de armas, que se compone de una caña grabada en el medio, y las barras de Aragon encima. Y en seguida a igual instancia de dichos caballeros regidores, pase a la puerta de la yglesia del combento de religiosas de San Gregorio orden de nuestro padre Santo Domingo, del que segun dixeron, es patron el ayuntamiento de dicha ciudad. Y en el portico de dicha yglesia y parte superior de el señalaron y se encuentran /19v./ dos escudos de armas en los dos lados de dicho portico, que se componen a saber es, el uno de ellos de una caña grabada tan solamente; y el otro de un castillo entre dos cañas, y las barras de Aragon encima. Y assimismo señalaron, y se encuentran en el arco de la porteria de dicho conbento otro escudo de armas que se compone de un castillo entre dos cañas; y las barras de Aragon encima [...]” [AHPZ, Pleitos Civiles, J13419-1, pieza 3, f. 19r.-v. (Alcañiz, 5-IV-1775)].

96. AHPZ, Pleitos Civiles, J13418-3, pieza 2, ff. 8v.-14v. (Alcañiz, 4-IV-1775), apéndice documental, doc. 4 .

97. AHPZ, Pleitos Civiles, J13418-3, pieza 1, f. 158r.-v. (Alcañiz, 23-V-1775). 
Pero este asunto llegó también a otros elementos del nuevo edificio, como el cancel que debía colocarse en el acceso situado en el brazo derecho del transepto, donde el Ayuntamiento no autorizó a que el Cabildo grabara sus armas -compuestas por la imagen de Nuestra Señora con el Niño en el trono, con una caña a cada lado, y debajo una tiara con dos llaves cruzadas y una media luna-, y tan solo permitió cincelar la imagen de Nuestra Señora, tal y como testificó el escultor Pedro Llovet, su autor, natural de Peñarroya de Tastavins (Teruel), de cuarenta y cinco años de edad y vecino de Alcañiz desde hacía dieciocho ${ }^{98}$.

Al final, la Real Audiencia, tras atender los alegatos de las dos partes ${ }^{99}$, refrendó la sentencia emitida el nueve de abril de 1767 -de la que ignoramos su contenido- y condenó al Cabildo de Santa María la Mayor a pagar las costas de la instrucción; y finalmente acabaron colocándose las armas de la ciudad como puede comprobarse en la actualidad ${ }^{100}$.

\section{El RESUltado FinAl: la ARQUitectura DE la COlEGiata DE AlCAÑIZ}

La irrupción del proyecto ideado por Felipe Sánchez para la nueva iglesia del Pilar de Zaragoza en el último cuarto del siglo XVII marcó un antes y un después en la concepción del falso salón en tierras aragonesas, un tipo alcanzado tras las reformas de la catedral zaragozana que estaba dotado de transepto -con lucernario en la encrucijada- elevado a la misma altura que el resto de naves ${ }^{101}$. Sánchez planteaba un templo basilical de tres naves, la central más ancha que las laterales, cubiertas con bóveda de cañón a la misma altura y un transepto adelantado en cuya encrucijada estaba prevista la elevación de una cúpula sobre pechinas. Tras esto, se retomaba el módulo basilical durante dos tramos y la cabecera -de perfil recto- estaba conformada por tres capillas, asimismo, de planta rectangular ${ }^{102}$.

Este modelo fue el que se adoptó -y adaptó- para la construcción de la iglesia parroquial de la Asunción de Cantavieja (Teruel), una obra de Antonio Nadal que fue edificada -integrando restos del templo anterior como la torre, la portada y el portegado- entre 1730 y 1745, de la que Domingo de Yarza -que estaba al

98. AHPZ, Pleitos Civiles, J13419-1, pieza 3, ff. 143r.-144v. (Alcañiz, 12-IV-1775).

99. AHPZ, Pleitos Civiles, J13418-3, pieza 1, ff. 624r.-270v. (Zaragoza, antes del 5-IX-1777), alegato del procurador del Cabildo; y ff. 283r.-299v. (Zaragoza, antes del 10-VII-1778), alegato de la parte del Ayuntamiento.

100. AHPZ, Pleitos Civiles, J13418-3, pieza 2, ff. 302r.-303v. (Zaragoza, 6-V-1779).

101. El resultado alcanzado por las reformas impulsadas por los arzobispos Alonso de Aragón entre 1490 y 1525, y Hernando de Aragón entre 1546 y 1550. El empleo de la seo de Zaragoza como modelo en IBÁÑEZ FERNÁNDEZ, Javier y ANDRÉS CASABÓn, Jorge. La catedral de Zaragoza de la Baja Edad Media al Primer Quinientos. Estudio documental y artístico. Zaragoza: Fundación "Teresa de Jesús", Cabildo Metropolitano de Zaragoza, 2016, pp. 142-144.

102. Usón GARCía, Ricardo. La intervención de Ventura Rodríguez en el Pilar: la Santa Capilla generatriz de un sueño. Zaragoza: Colegio Oficial de Arquitectos de Aragón, 1990, pp. 40-47. 
cargo de las obras de la basílica zaragozana- dijo que «de su traza no he visto ninguna ni aun en Roma ${ }^{103}$, algunos años antes de que idease el plan para la colegiata alcañizana, donde colocó el coro en el segundo tramo de la nave e introdujo el deambulatorio tras el retablo mayor, al igual que en el Pilar y en Cantavieja.

Los ejemplos de Cantavieja y Alcañiz convivieron con el modelo más extendido en el Bajo Aragón, el de iglesia de tres naves a la misma altura con el transepto retrasado, que ya estaba presente en las iglesias de Muniesa, La Fresneda y Calaceite, tres edificios que alcanzaron su configuración definitiva a finales del Seiscientos. En cualquier caso, este modelo, pero adaptado a los nuevos gustos impuestos por la construcción de la basílica zaragozana, puede encontrarse en las iglesias parroquiales de Belmonte de San José (Teruel), diseñada por Miguel de Aguas y Valero Catalán en la década de los treinta del siglo XVIII ${ }^{104}$, o en la de Mas de las Matas (Teruel), trazada por José y Francisco Dolz entre 1734 y $1744^{105}$; y que continuó durante toda la centuria, traspasando incluso los preceptos académicos, como sucedió en las iglesias parroquiales de las localidades turolenses de Seno y Allepuz, que se edificaron en torno a $1770^{106}$.

Además, la combinación de la planta del Pilar con otras soluciones, como la planta central, terminó generando un tipo de iglesia con cabecera triconque que, sin embargo, por la disposición retrasada del transepto, el protagonismo de la cúpula de la encrucijada y el presbiterio, continuaba remitiendo, tanto tiempo después, al modelo de la Seo de Zaragoza, como en la iglesia de los franciscanos de Alcañiz; en varias iglesias de la provincia de Castellón, como en la arciprestal de Villarreal y en la parroquial de Cinctorres; o en la de Tarragona, como en las de Batea -donde tomó parte fray Atanasio-, o Corbera de Ebro, donde todas ellas fueron construidas por maestros aragoneses como Juan José Nadal ${ }^{107}$, José Dolz y José Ayora ${ }^{108}$ o Francisco Melet ${ }^{109}$.

103. Gil SAuRA, Yolanda. Arquitectura barroca en Castellón. Castellón: Diputación de Castellón, 2004, p. 197.

104. ThOmSon Llisterri, Teresa. Las artes en el Bajo Aragón en la segunda..., op. cit., pp. 70-73.

105. Gil Domingo, Agustín. "Documentos inéditos de la fiel villa de Mas de las Matas». Boletín del Grupo de Estudios Masinos, 1992, 12, pp. 7-192.

106. Sobre Seno, véase Martín Costea, Antonio; AÑón SERrano, Andrés; Oliveros Mor, José Luis y Díaz SORO, Francisco Javier. "Datos históricos sobre la iglesia parroquial de Seno (Teruel)". Mas de las Matas, 1993, 13, pp. 285-326; y sobre Allepuz, véase GIL SAURA, Yolanda. "El paisaje barroco de las Bailías: parroquias, ermitas y conventos». Baylias. Miscelánea del Centro de Estudios del Maestrazgo, 2014-2016, 10, pp. 125-142, espec. pp. 134-135.

107. Sobre la actividad de este maestro en tierras de Castellón, véase GIL SAURA, Yolanda. Arquitectura barroca..., op. cit., pp. 201-212; y la realizada en Aragón en MARTín MARCO, Jorge. «El arquitecto Juan José Nadal en Aragón (ca. 1735-1751)». Academia, 2019, 121, pp. 89-109.

108. GIl SAURA, Yolanda. Arquitectura barroca..., op. cit., pp. 357-361.

109. Alanyá, Josep. "Església...”, op. cit., pp. 323-337; GIL SAURA, Yolanda y LlorCa i MarTí, Alfons. "L'església parroquial de Sant Pere de Corbera». En HTE. Historia de les Terres de l'Ebre, Art $i$ cultura, 5. Tortosa: Universitat Rovira i Virgili, Fundació Ilercavonia Futur, Aeditors, pp. 179-180. 


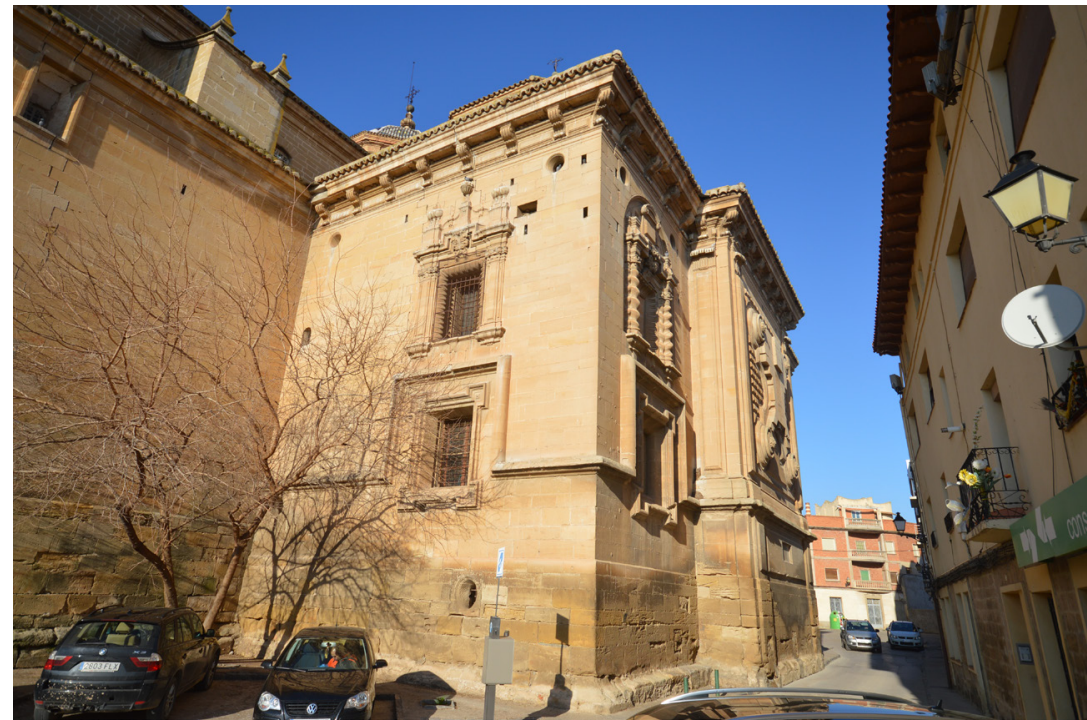

Fig. 1. Alcañiz (Teruel). Iglesia de Santa María la Mayor. Capilla de la Soledad. Exterior. Fotografía: Jorge Martín Marco.

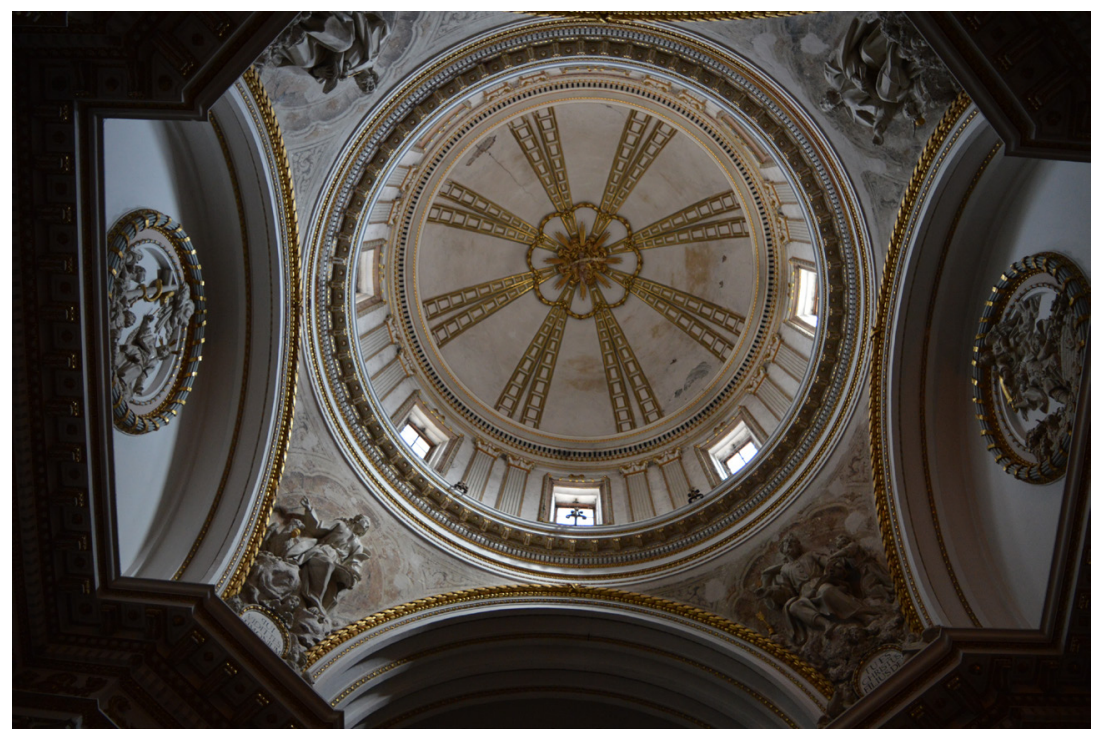

Fig. 2. Alcañiz (Teruel). Iglesia de Santa María la Mayor. Capilla de la Soledad. Interior. Fotografía: Jorge Martín Marco. 
EL PROCESO CONSTRUCTIVO DE LA COLEGIATA DE SANTA MARÍA LA MAYOR DE ALCAÑIZ (TERUEL)...

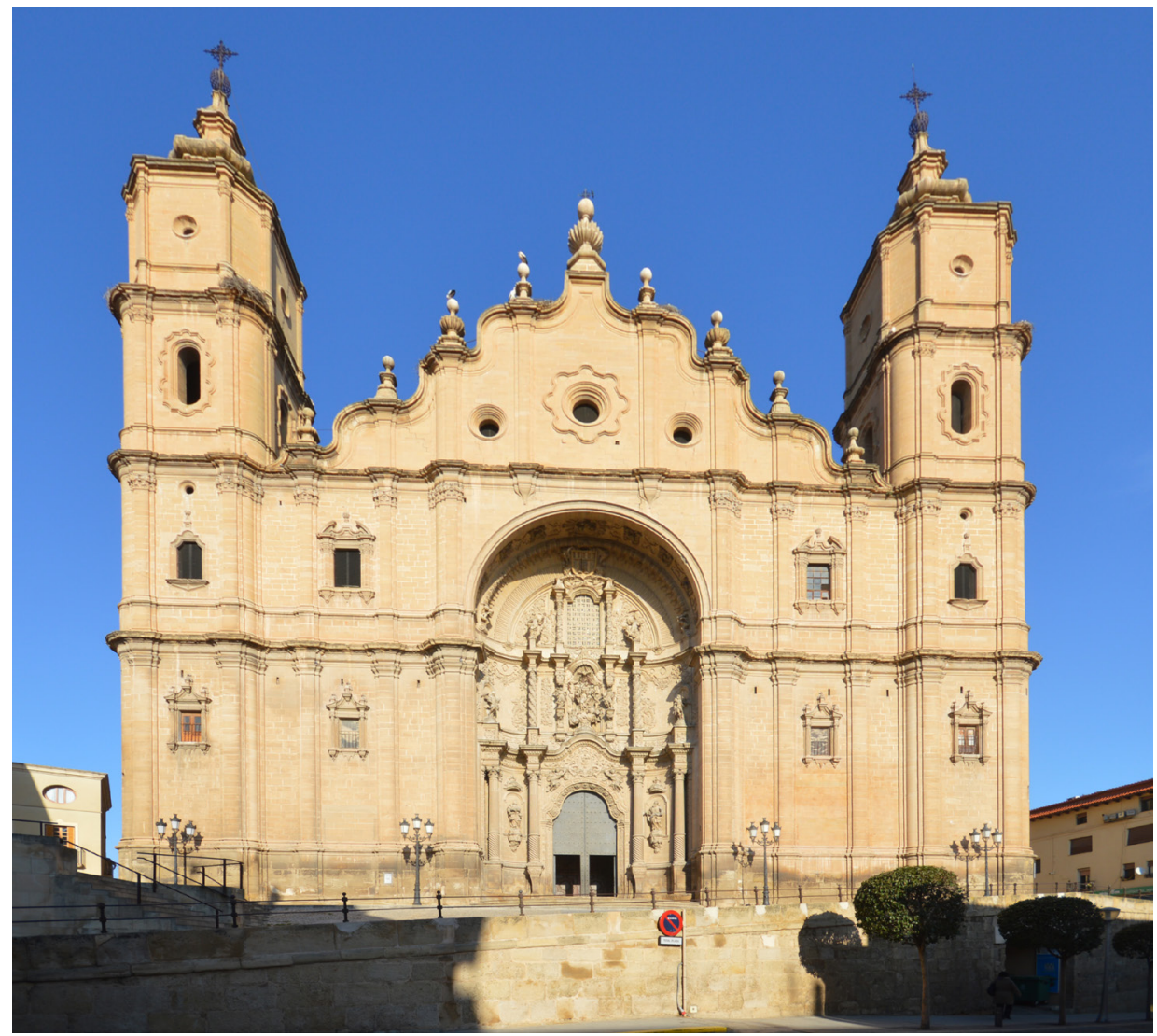

Fig. 3. Alcañiz (Teruel). Iglesia de Santa María la Mayor. Exterior. Fotografía: Jorge Martín Marco. 


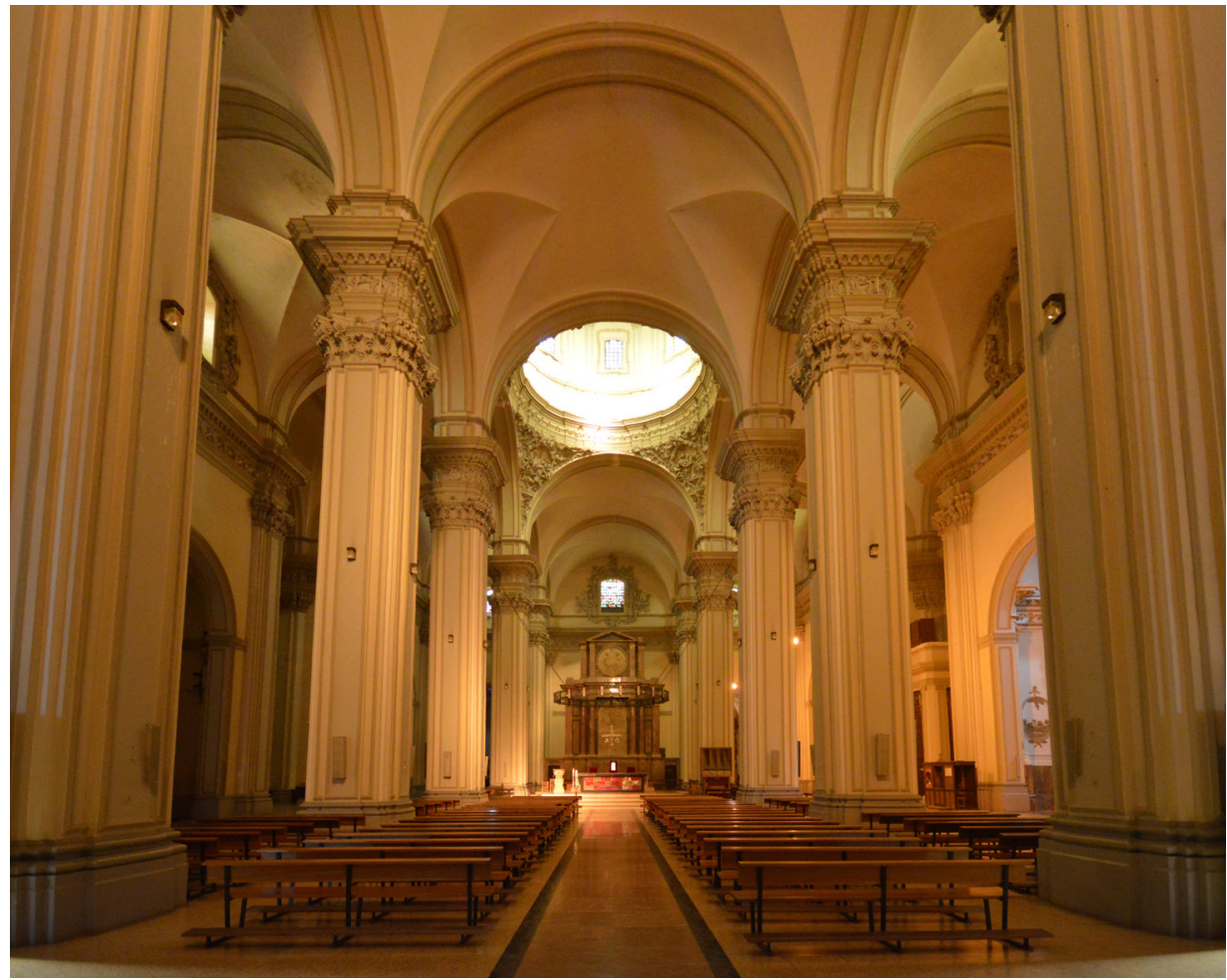

Fig. 4. Alcañiz (Teruel). Iglesia de Santa María la Mayor. Interior. Fotografía: Jorge Martín Marco. 
EL PROCESO CONSTRUCTIVO DE LA COLEGIATA DE SANTA MARÍA LA MAYOR DE ALCAÑIZ (TERUEL)...

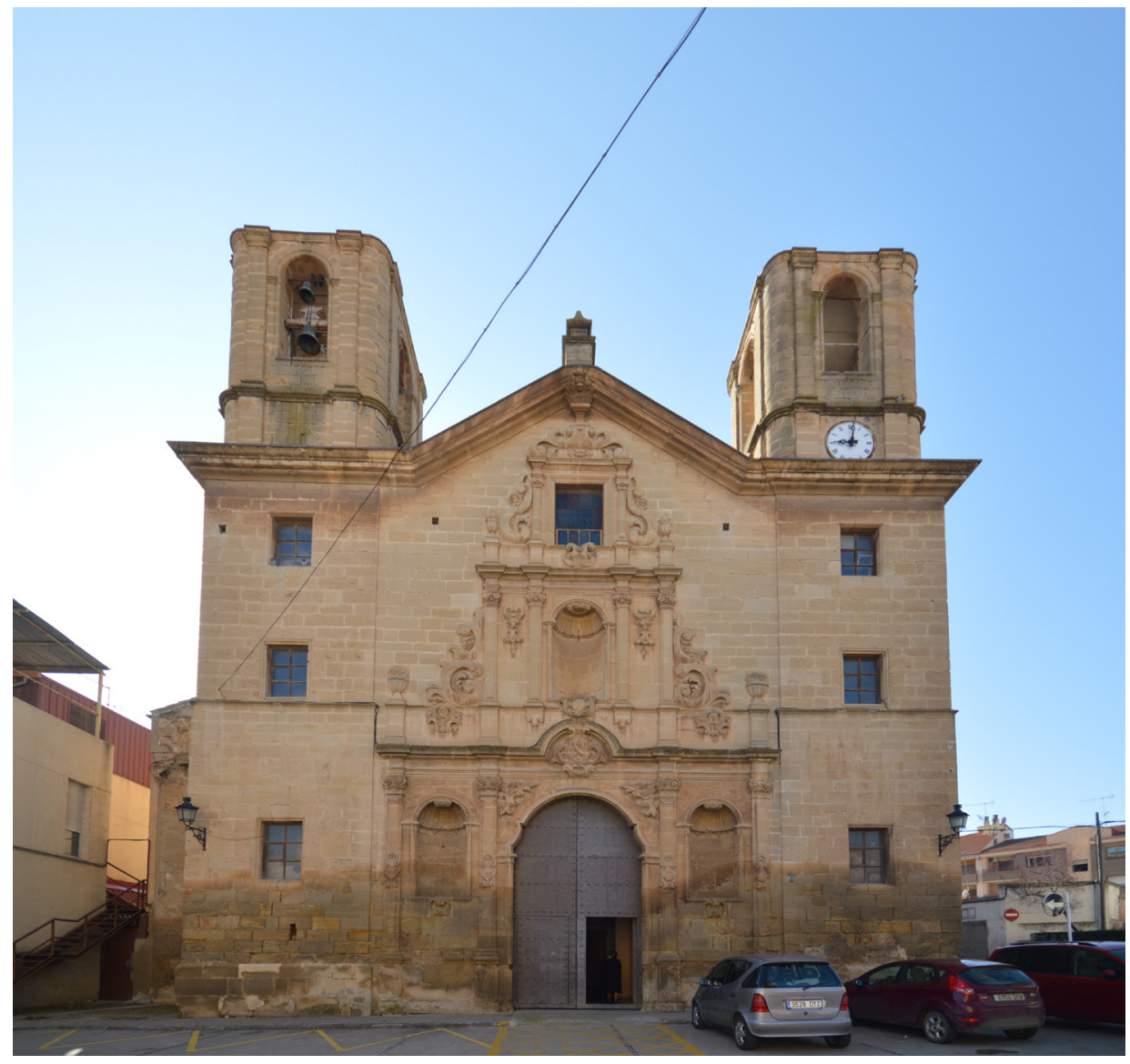

Fig. 5. Alcañiz (Teruel). Iglesia de San Francisco. Exterior. Fotografía: Jorge Martín Marco. 


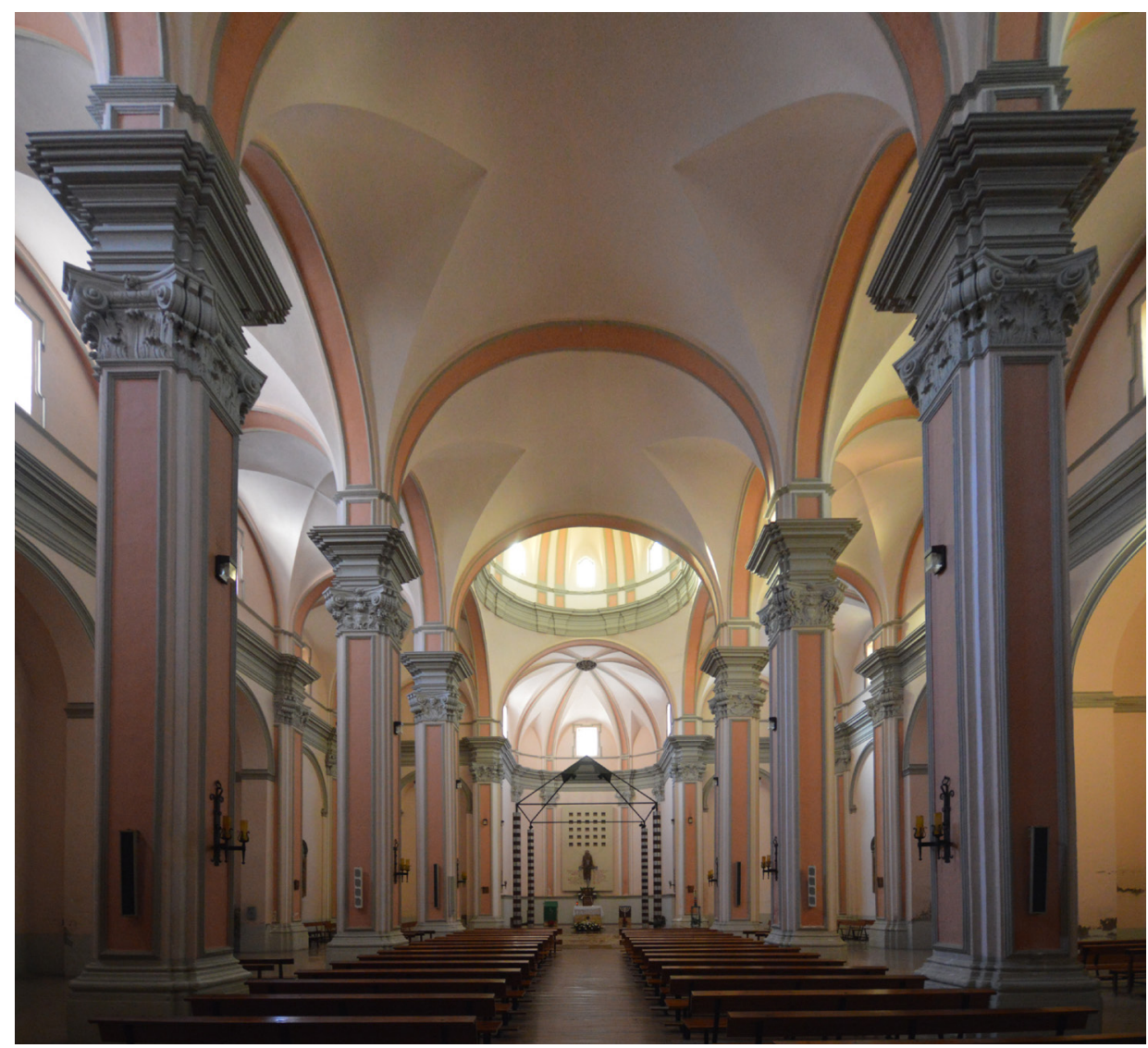

Fig. 6. Alcañiz (Teruel). Iglesia de San Francisco. Interior. Fotografía: Jorge Martín Marco. 
EL PROCESO CONSTRUCTIVO DE LA COLEGIATA DE SANTA MARÍA LA MAYOR DE ALCAÑIZ (TERUEL)...

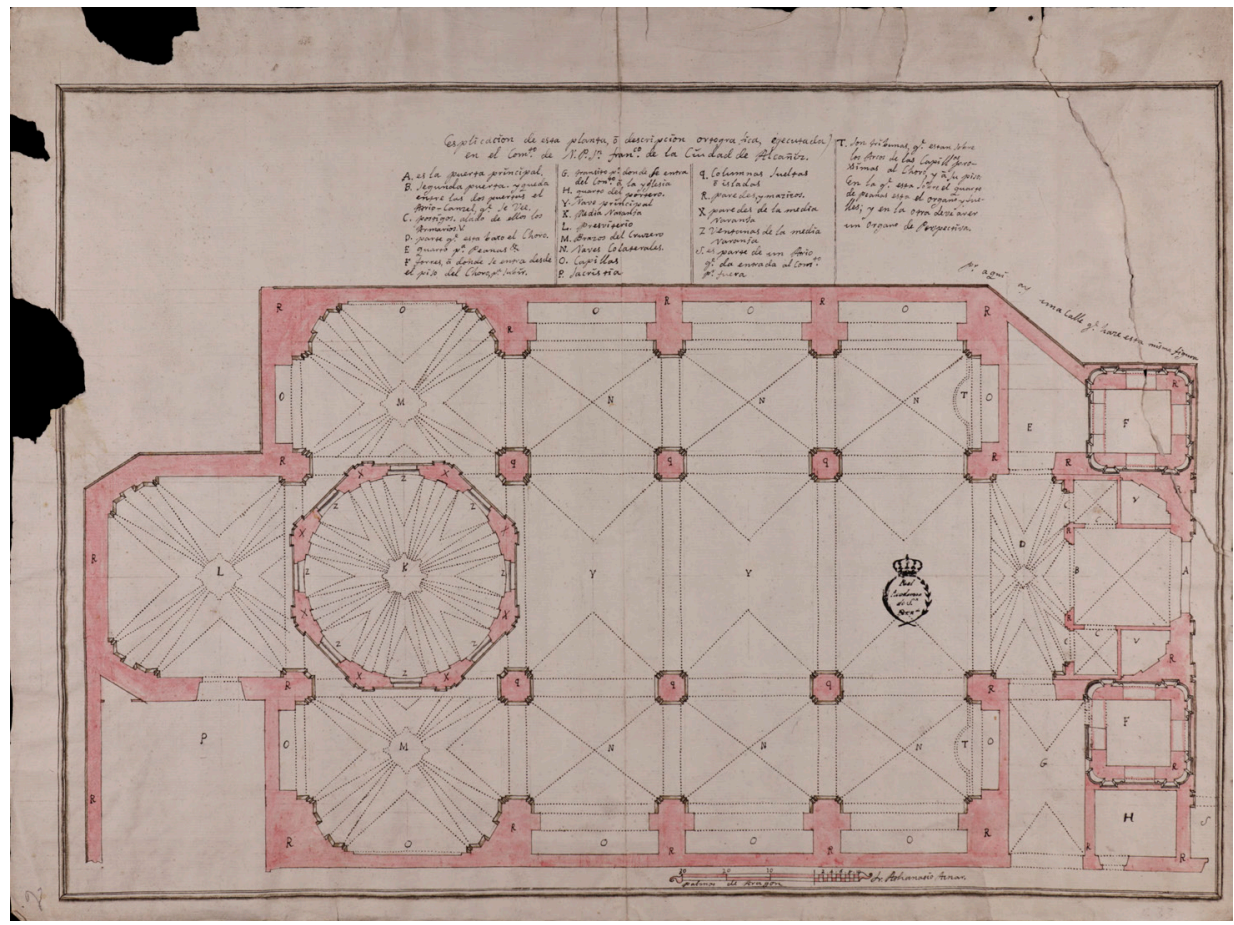

Fig. 7. Fray Atanasio Aznar. Iglesia del convento de N. P. San Francisco de la ciudad de Alcañiz, signatura A-4378, 1758. Papel verjurado, tinta sepia y aguadas rosa y crema. 43,9 x 58,8 cm. Museo de la Real Academia de Bellas Artes de San Fernando. 


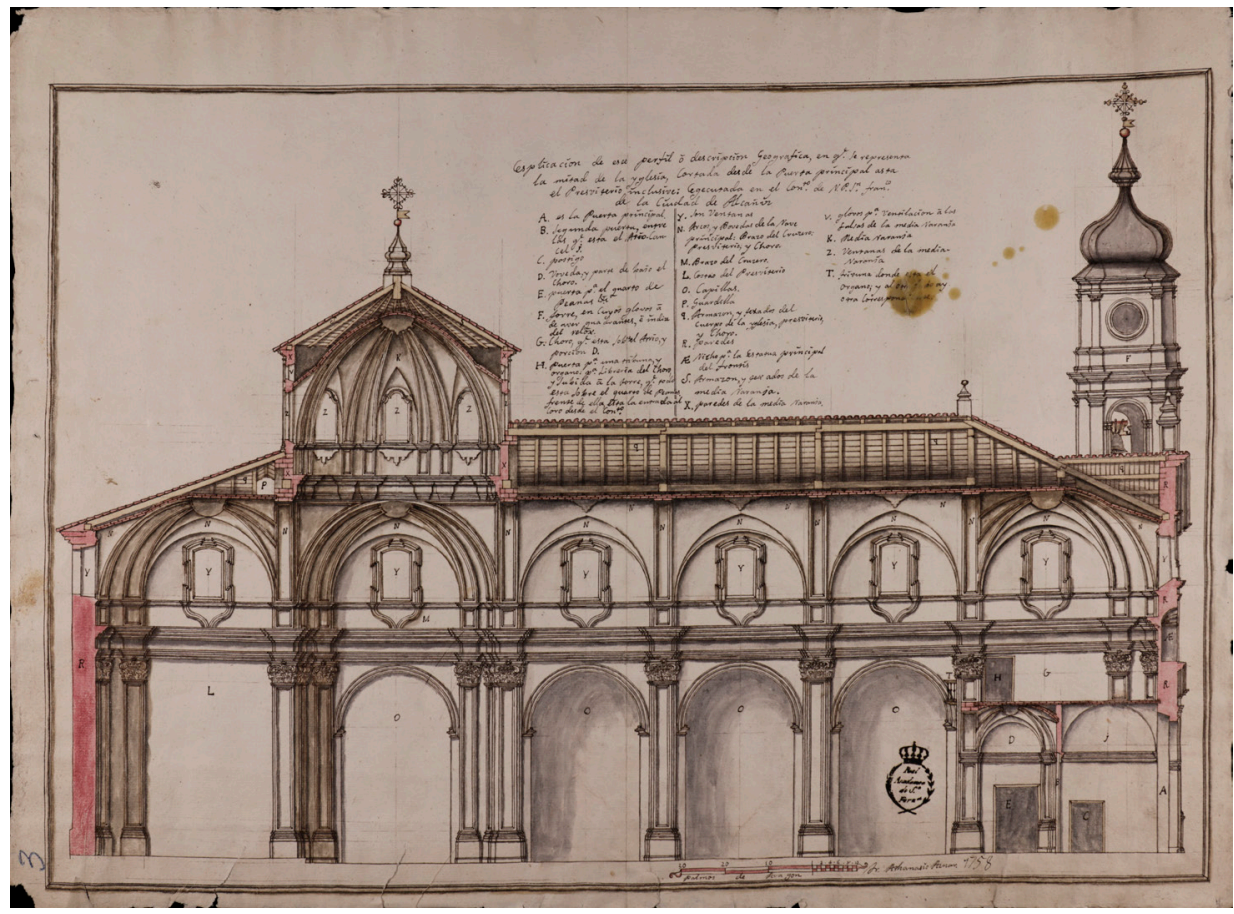

Fig. 8. Fray Atanasio Aznar. Iglesia del convento de N. P. San Francisco de la ciudad de Alcañiz, signatura A-4379, 1758. Papel verjurado, tinta sepia y aguadas rosa y crema. 43,5 x $58,3 \mathrm{~cm}$. Museo de la Real Academia de Bellas Artes de San Fernando. 


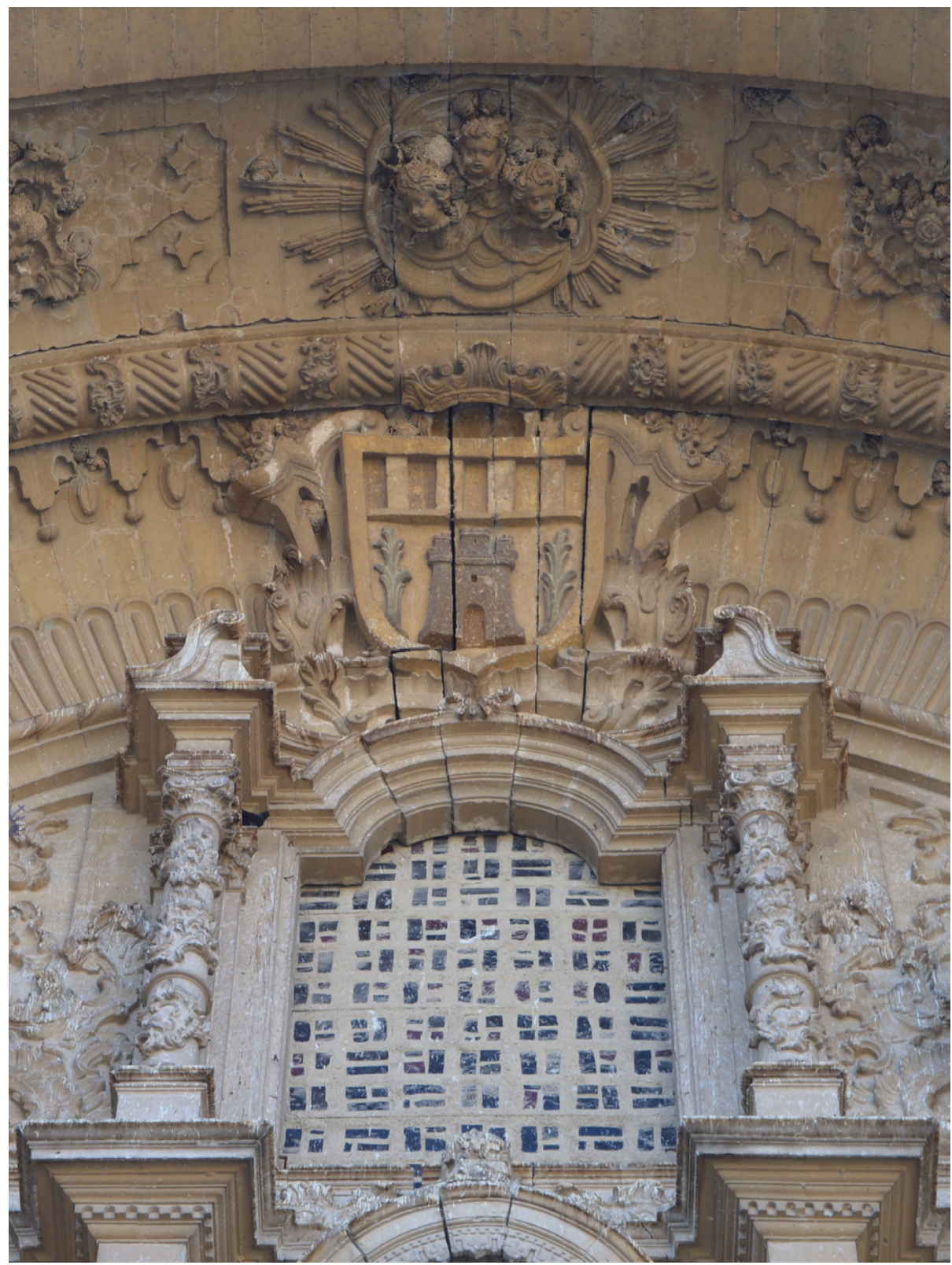

Fig. 9. Alcañiz (Teruel). Iglesia de Santa María la Mayor. Exterior. Escudo de armas de la ciudad. Fotografía: Jorge Martín Marco. 


\section{BiBLIOGRAFÍA}

Abós Castel, M. ${ }^{a}$ Pilar y Micolau Adell, José Ignacio. «Documentos sobre la participación municipal en la construcción de la Iglesia Colegial de Alcañiz». Boletín del Centro de Estudios Bajoaragoneses, 1981, 1, pp. 97-106.

Alanyá, Josep. "Església de Batea (Bisbat de Tortosa. Prov. de Tarragona). Contracte de construcción". Boletín de la Sociedad Castellonense de Cultura, 2006, 82, pp. 323-340.

Almería, José Antonio et al. Las artes en Zaragoza en el último tercio del siglo XVII (1676-1696). Estudio documental. Zaragoza: Institución Fernando el Católico, 1983, pp. 179-180.

Arbaiza Blanco-Soler, Silvia y Heras Casas, Carmen. "Inventario de los dibujos de arquitectura (de los siglos XVIII y XIX) en el museo de la Real Academia de Bellas Artes de San Fernando (V).. Academia, 2004, 98-99, pp. 121-262.

CORTÉs BORROY, Francisco Javier. «El Barroco en la Comarca del Bajo Aragón Caspe: algunos documentos inéditos conservados en el Archivo de Protocolos Notariales de Caspe». Cuadernos de Estudios Caspolinos, 2009, 28, pp. 223-258.

Fernández Agudo, María Pilar y SÁnchez de LEÓn Fernández, María Ángeles. «Índice de cargos académicos de la Real Academia de Bellas Artes de San Fernando en el siglo XVIII. Academia, 1988, 67, pp. 371-458.

Gil Domingo, Agustín. «Documentos inéditos de la fiel villa de Mas de las Matas». Boletín del Grupo de Estudios Masinos, 1992, 12, pp. 7-192.

GIL SAURA, Yolanda. Arquitectura barroca en Castellón. Castellón: Diputación de Castellón, 2004 .

GIL SAURA, Yolanda. "El paisaje barroco de las Bailías: parroquias, ermitas y conventos». Baylias. Miscelánea del Centro de Estudios del Maestrazgo, 2014-2016, 10, pp. 125-142.

GIL SAURA, Yolanda y LlorCa I MARTí, Alfons. "L'església parroquial de Sant Pere de Corbera». En HTE. Historia de les Terres de l'Ebre, Art i cultura, 5. Tortosa: Universitat Rovira i Virgili, Fundació Ilercavonia Futur, Aeditors, 2010, pp. 179-180.

González Hernández, Vicente. Noticias histórico-artísticas de Alcañiz. Siglos XVII y XVIII. Alcañiz: Centro de Estudios Bajoaragoneses, 1994.

IBÁÑEZ FERNÁNDEZ, Javier y ANDRÉS CASABÓn, Jorge. La catedral de Zaragoza de la Baja Edad Media al Primer Quinientos. Estudio documental y artístico. Zaragoza: Fundación «Teresa de Jesús», Cabildo Metropolitano de Zaragoza, 2016, pp. 142-144.

IBÁÑEZ FERnÁNDEZ, Javier y MARTín MARCO, Jorge. "El antiguo retablo mayor de la colegiata de Alcañiz (Teruel): Jaime Romeu, Domingo y Tomás Ram. 1470-ca. 1486» (en prensa).

IBÁÑEZ FERnÁNDEZ, Javier y SuTERA, Domenica. «Entre Gaspar Serrano y Giovanni Battista Contini: la reforma barroca del campanario de la catedral de Zaragoza». Anuario del Departamento de Historia y Teoría del Arte, 2010, XXII, pp. 189-208.

LONgás LaCASA, M. ${ }^{a}$ Ángeles. "Las Artes en Aragón en el siglo XVII según el Archivo de Protocolos Notariales de Zaragoza. De 1631 a 1633». En BRuÑén IBÁÑEZ, A. I.; Julve Larraz, L. y Velasco de la PEÑa, E. (coords.). Las Artes en Aragón en el siglo XVII según el Archivo de Protocolos Notariales de Zaragoza. Zaragoza: Institución «Fernando el Católico", vol. VII, 2006.

Magdalena Lacambra, Federico. La iglesia colegiata de Alcañiz. Apuntes históricos. Zaragoza: El Noticiero, 1944. 
Martín Costea, Antonio; AÑón Serrano, Andrés; Oliveros Mor, José luis y Díaz Soro, Francisco Javier. «Datos históricos sobre la iglesia parroquial de Seno (Teruel)«. Mas de las Matas, 1993, 13, pp. 285-326.

MARTín MARCO, Jorge. "La circulación de maestros franceses entre las diócesis de Zaragoza y Tortosa durante los siglos XVI y XVII. El caso de Pedro Pizarro". Archivo de Arte Valenciano, 2018, XCIX, pp. 87-109.

MARTín MARCO, Jorge. "La formación de los profesionales de la construcción en la Zaragoza del Barroco: los exámenes del pleito de Manuel Casanova y Francisco López contra el gremio de albañiles (1764-1767)». Artigrama, 2018, 33, pp. 257-298.

MARTín MARCO, Jorge. "Aportaciones documentales sobre los maestros de la iglesia de la Asunción de Gandesa (Tarragona) entre 1698 y 1701». Recerca, 2019, 18, pp. 35-53.

MARTín MARCO, Jorge. «Arquitectura para dos carismas distintos en el Bajo Aragón turolense en el Seiscientos: el convento carmelita de Alcañiz y el descalzo del Desierto de Calanda". Ars Longa, 2019, 28, pp. 91-107.

Martín MarCo, Jorge. «El arquitecto Juan José Nadal en Aragón (ca. 1735-1751)». Academia, 2019, 121, pp. 89-109.

MARTín MARCO, Jorge y Gil Bordás, José Ángel. «La antigua iglesia colegial de Alcañiz: un ejemplo de promoción artística en el medievo aragonés». En IBÁÑEZ FERNÁNDEZ, Javier (coord. y ed.). Del mecenazgo a las nuevas formas de promoción artística. Actas del XIV Coloquio de Arte Aragonés. Zaragoza: Prensas de la Universidad de Zaragoza, 2017, pp. 263-280.

MuÑOz SEBASTIÁ, Joan Hilari. La construcció del convent franciscà de Jesús (1732-1792). Els fonaments d'un poble. Tortosa: EMD de Jesús, 2014.

PUIG SANCHIS, Isidro. "Los Burria. Maestros alarifes aragoneses en la Lleida del siglo XVIII". Boletín del Museo e Instituto Camón Aznar, 2004, 94, pp. 329-278.

SAmBricio, Carlos. La arquitectura española de la Ilustración. Madrid: Consejo Superior de los Colegios de Arquitectos de España, 1986.

THOMSON LLISTERRI, Teresa. Las artes en el Bajo Aragón en la primera mitad del siglo XVIII. Estudio documental. Alcañiz: Centro de Estudios Bajoaragoneses, 1998.

THOmson LlisterRI, Teresa. Las artes en el Bajo Aragón en la segunda mitad del siglo XVIII. Estudio documental. Alcañiz: Centro de Estudios Bajoaragoneses, 2002.

Thomson Llisterri, Teresa. Iglesia de Santa María la Mayor. Alcañiz: Centro de Estudios Bajoaragoneses, 2006.

VIDIELla y JASÁ, Santiago. Recitaciones de la historia política y eclesiástica de Calaceite. Calaceite: Ayuntamiento de Calaceite, Familia Jassá, 1996.

\section{APÉNDICE DOCUMENTAL}

1629, agosto, 23

Alcañiz

Capitulación y concordia entre los jurados de la villa de Alcañiz, de una parte, y Claudio Genequi, platero, habitante de presente en la dicha villa, de otra parte, sobre la realización de una custodia. 
Archivo Histórico Provincial de Zaragoza [AHPZ], Pleitos Civiles, J13418-3, ff. $24 \mathrm{v} .-27 \mathrm{r}$.

[Al margen: Escritura de contratta con el platero sobre la custodia en 23 de agosto 1629]

Die vigessimo tercio mensis augusti anno M.D.C.XXVIIII Alcagnilif [sic] ante la presencia de mi Francisco de Olit notario publico ettc y de los testigos infrascritos parecieron personalmente constituidos los ilustres señores Geronimo de Heredia, Anttonio /25r./ Balaguer Pedro Perez de Peralta, y Domingo Salbador jurados que de presente son de dicha villa, de una partte, et Claudio Genequi platero vecino de la ciudad de Zaragoza, y de presente hallado en dicha villa de Alcañiz de partte otra; los quales encaminando sus palabras hacia mi dicho Francisco de Olit notario dixeron tales y semejantes palabras, que enttre ellos havian hecho ordenar al doctor micer Joan de Valettas adbogado que de presente es de dicha villa una capitulacion y concordia con algunos pactos y condiciones en aquella contenidos, la qual, vista, leida y examinada por los dichos señores jurados y el dicho Claudio Genequi como partes interesadas en ella, la dieron y libraron en poder y manos de mi dicho Francisco de Olit notario originalmente la qual y todo lo en ella conttenido, de palabra â palabra es del /25v ./ tenor infrascripto y siguiente

[Al margen: Cedula de pactos] Capitulacion y concordia hecha y pactada entre los ilustres señores jurados de la villa de Alcañiz de una parte, y Claudio Genequi platero havitante de presente en la dicha villa de la otra acerca de una custodia que dichos señores jurados y consexo han deliverado de hazer y dado a que le haga dicho Claudio Genequi con las condiciones y de la manera siguiente

Et primo es pactado, y concordado entre las dichas partes que el dicho Claudio Genequi se haya de obligar y obligue juntamente con Joaquina Alexandre su muger, y Geronimo Genequi su hijo mediante instrumento publico de comanda en fabor de los señores jurados que son y por tiempo seran de dicha villa en la suma y canttidad de veinte mil sueldos jaqueses para seguridad de todos los cabos conttenidos en la presente capitulacion y de aquello que le fuere entregado assi en dinero como en plata para cumplimiento de una custodia que ha de hacer conforme la traza que tiene dada /26r./ y que ba firmada de mano de dichos señores jurados y queda en su poder, y asimismo firmada de mano de dicho Claudio Genequi, con contracarta que se le ha de otorgar de no balerse de dicha comanda, sino es para el cumplimiento de fin de dicha obra, ô de aquello que falttare â cumplimir segun lo trattado, y capitulado con el dicho Claudio Geniqui; Y assimismo para en caso de su muerte, para poder rescivir, y cobrar aquello que tubiere en su poder, disfalcando de aquello los trabajos que tuviere hechos y puestos en dicha obra

Ittem es pactado, y concordado que se le haya de entregar por los dichos señores jurados mil onzas de plata, y algo mas si fueren menester al dicho maestro; en cada vez cien onzas de plata por lo menos, ô lo que mas paresiere a los dichos señores jurados 
Ittem esta pactado y concordado se le hayan de pagar por las hechuras de dicha custodia, en lo que esttá concertado por los señores jurados que son y por tiempo seran que es catorce mil sueldos jaqueses pagaderos por enttero al fin y quando estuviere acabada dicha custtodia; y en el entretantto para ayuda de su costa /26v./ y de sus oficiales aquello que pareciere a dichos señores jurados

Ittem es pactado que se le haya de dar una casa en la villa de Alcañiz para trabajar en la parte que a los señores jurados paresciere, y licencia para corttar la madera y hacer carbon necesario para dicha obra, sustento de su casa

Ittem el dicho Claudio Genequi queda obligado, y por la presente se obliga haver de dar acabada dicha custodia de buena platta segun, y conforme se le entregare, y de la ley y marca de la dicha villa [al margen: símbolo] sin mezcla ni mistura de otro metal excepto las piezas y cosas que paresciere a los señores jurados se hagan de otro mettal las quales se haya de declarar por escritura y firmadas por uno de los secretarios de dicha villa, y que las figuras que se han de poner en dicha custodia que son seis y la campanilla, y las quatro garras del pie esta obligado a dorarlas parecien de $/ 27 r$. a los señores jurados y dandole el oro; y ha de dar acabada dicha custodia dentro tiempo y hasta la vispera del Corpus primero viniente del año mil seiscientos y treinta; y la dicha custodia ha de quedar en su perfeccion y conforme el arte y para el conocimiento de lo dicho y si esta bien puesta en perfeccion haya de nombrar dos personas buenos artifices y peritos en el arte nombraderos el uno por los señores jurados y el otro por el dicho Claudio Genequi; y en caso de discordia puedan nombrar los dos un tercero

Ittem es pactado que puedan los señores jurados para hacer cotejo de lo que se trabaja y del dinero y plata que se le huviere entregado, reconocer las piezas y pedazos de custodia que estubiere trabajado, para que conforme a ello se le pueda entregar mas plata y dinero, y para animar al dicho maestro que continue dicha obra hasta que aquella este acabada y para que con /27v./ mayor seguridad se pueda escargar la villa en aumentarselo todo lo que fuere posible Geronimo de Heredia jurado $=$ Antonio Balaguer jurado $=$ Pedro Perez de Peralta jurado $=$ Domingo Salbador jurado quarto $=$ Yo Claudio Genequi otorgo dicha capitulacion $=$ Francisco de Olit secretario $=$

[Al margen: Prosigue la escritura] Et assi dada y librada por dichas partes interesadas la dicha capitulacion y concordia dixeron que aquella hacian firmaban y otorgaban como de hecho hicieron firmaron, y otorgaron la dicha y presente concordia, y todas, y cada unas cosas en aquella contenidas desde la primera linea hasta la ultima de aquella; los quales prometieron tener serbar y cumplir; a saber es lo que a cada una de dichas partes a su parte toca y les pertenece a firmar, y otorgar tener serbar y cumplir singula singulis pro ut conbenit referendo; et si por no tener y cumplir lo que a cada una de dichas partes toca etc costas algunas etc aquellas prome/28r./tieron y se obligaron dichas partes y cada una de ellas pagar etc de los quales y de las quales etc a lo qual tener serbar y cumplir obligaron; a saber es los dichos señores jurados los bienes y rentas de dicha villa muebles y sitios etc, y el dicho Claudio Genequi su persona y bienes muebles y sitios los 
quales etc bien assi como etc quisieron que la presente obligacion sea especial etc en tal manera etc con clausulas de aprehension, manifestacion etc inventario y otras clausulas en semejantes actos poner acostumbradas etc renunciaron etc jusmetieronse etc quisieron sea bariado juicio con poder de reglar non obstantibus etc fiat large etc

Testes Juan Luis Lopez notario y Pedro Ardiz vezinos de la villa de Alcañiz

1733, noviembre, 14

Alcañiz

Miguel de Aguas, maestro de obras, vecino de la ciudad de Alcañiz, se compromete y obliga a derribar y construir de nuevo la columna de la insigne iglesia colegial de Santa María la Mayor de dicha ciudad, que estaba contigua al coro enfrente de su sala capitular y que amenazaba ruina.

Archivo Histórico de Protocolos de Alcañiz [AHPA], Pablo Alberto Suñer, 1733, ff. 219r.-220v.

[Al encabezamiento: Die XIIII mensis novembris anno domini M.DCC.XXXIII Alcagnitii]

[Al margen: En seis de febrero de mil setecientos settenta y dos di traslado de esta escritura en papel del sello segundo y la entregue a $(l)$ procurador general de esta ciudad de que doy fee (suscripción autógrafa: Suñer y Añon comisario)]

Eodem die que yo Miguel de Aguas maestro de obras vecino de la ciudad de Alcañiz de grado y de mi cierta ciencia certificado de todo mi drecho, y en aquellas mejores via modo forma y manera que de fuero, y drecho hacerlo puedo y debo, prometo y me obligo derrivar y de nuevo construir la columna de la ynsigne yglesia colegial de Santa Maria la Mayor de esta dicha ciudad de Alcañiz que es la que esta contigua al choro de dicha yglesia enfrente de su sala capitular y que amenza ruina; cuia obra y construccion prometo y me obligo hacer en la forma y por el precio, y con los pactos y condiciones siguientes

Primeramente prometo y me obligo derrivar y que derrivare dicha columna y de nuevo la creare de piedra labrada uniforme y correspondiente con su vasa y capitel desde el pavimento hasta el arrancamiento de los arcos, todo sin lession de la demas fabrica; y si por culpa mia sobreviniesse alguna ruina en la dicha parte de obra correspondiente, sera de mi cuenta su reparo y composicion y toda la obra dexarla âssegurada a reconocimiento de maestros alarifes peritos

Ittem es pacto que sera de mi cuenta a coste y costas comprar conducir y disponer todos los materiales conducentes y necessarios tanto para derrivar y crear dicha columna, quanto para apuntalar y asegurar /219v./ los arcos y bobedas que corresponden â ellas para cuio fin podre cortar hasta unos veinte maderos en el vedado que me faltan. Y tambien sera de mi cuenta mandar hacer y coçer en la 
texeria vecina al conbento de San Francisco los ladrillos que fueren necesarios para dicha obra. Pero que ni la ciudad, ni vecino se me puedan llevar ladrillo alguno que primero yo no haya tomado los que fueren menester. Y si el texero fuere omisso, ô se negasse en hacerlos o cozerlos que la ciudad me haga el favor de mandarle trabajar

Ittem es pacto: que la dicha obra la hare y cumplire y concluire por la cantidad de nuevecientas libras jaquesas; cuio importe recibire de el producto que dan las primicias de dicha ciudad en los plazos frutos efectos y precios que debe pagar el arrendador â la ciudad segun escritura de arrendamiento

Ittem es pacto que siempre que la junta mande que se me entregue la cantidad que le pareciere, dare luego principio â la prevencion de materiales, y recogidos y aprontados dare concluida dicha obra dentro de tres meses hacenderos que se contaran desde el dia primero que empezare â crehar los pilares, ô, apuntalar con cuios pactos, condiciones y obligaciones prometo y me obligo derrivar y construir de nuevo la referida columna en la forma y manera sobredicha y al cumplimiento de todo lo sobredicho obligo mi persona y todos mis bienes, assi muebles, como sitios donde quiere havidos y por haver los quales quiero aqui haver /220r./ y he por nombrados y confrontados y todos por especialmente obligados hipotecados devidamente y segun fuero de este reyno de Aragon y que esta obligacion sea especial, y surte y tenga el efecto que segun dicho fuero surtir y tener puede y debe y reconozco y confiesso tener y poseher dichos bienes nomine precario y de constituto por los ilustres señores corregidor y regidores de la presente ciudad y sus havientes drecho de tal manera que la posession civil y natural mia sea havida por suia y con sola esta escritura puedan ante qualquiere juez competentes aprehender dichos mis bienes sitios executar ynventariar emparar y sequestrar los muebles y obtener sentencias en favor en qualquiere procesos que intentaren siguiendo las apelaciones y en virtud de dichas sentencias poseher y usufructuar dichos bienes, hasta ser pagados de todo lo que por razon de lo sobredicho se les debiere con mas las costas intereses daños que por razon de ello en qualquiere manera se les hubieren ocasionado y renuncio a mis propios juezes ordinarios y locales y al juicio de aquellos y me jusmeto por la dicha razon a la jurisdiccion y conocimiento de qualesquiere juezes y justicias de su magestad superiores ê inferiores de el presente reyno de Aragon, y especialmente a los señores regente /220v./ y oidores de la Real Audiencia de el, ante quien es por la dicha razon mas demandar y convenirme querran ante los quales cada uno de dichos señores juezes prometo y me obligo hacer entero cumplimiento de drecho y de justicia. Y quiero sea variado juicio de un juez â otro, y otras â costas mias una muchas vezes, y que el juicio ante un juez comenzado, no embaraçe al otro, u otros antes bien todos puedan concurrir en un mismo tiempo y ser deducidos a debido efecto no obstante qualquier fuero ley o drecho que lo contrario dispongan fiat large etc

Testes Bernardo Comas y Valero Dextre, havitantes en la dicha ciudad de Alcañiz

[Suscripción autógrafa: Yo Miguel de Aguas otorgo lo sobredicho] 
[Suscripción autógrafa: Yo Bernardo Comas soi testigo de lo sobredicho y firmo por Balero Dextre mi contestigo, que dixo no sabia escribir]

Attesto que en el presente acto no hay que salbar segun fuero

[Suscripción autógrafa: Suñer]

1775, abril, 3

Alcañiz

Comparecencia de Pantaleón Arcayne y Joseph Gorrita por los sitios y parages de la ciudad de Alcañiz donde se encuentran los escudos de armas de dicha ciudad.

AHPZ, Pleitos Civiles, J13419-3, ff. 8r.-14r.

[Al margen: Comparecencia de don Pantaleon Arcayne y don Joseph Gorrita y requerimiento para que pase a los sitios y parages de la presentte ciudad en que se hallan grabadas sus armas]

En dicha ciudad de Alcañiz el mismo dia tres de abril de dicho y corriente año mil settezientos setenta y cinco ante mi el infrascripto esscribano recettor se presenttaron don Pantaleon Arcayne abogado de los reales consexos y don Joseph Gorrita ambos caballeros regidores de la misma ciudad. y aceptando el / $8 v$./ encargo y comision que se les tenia dada por el ayuntamiento para suministrar la probanza de compulsas, y testigos que tenia y tiene ofrecida en el pleito de firmas que sigue con el Cabildo de la yglesia colegial de dicha ciudad dixeron estan pronto a señalar los sitios y parages de la presente ciudad en que por la misma se tienen puestas esculpidas, y fixadas las armas de que ha usado y usa; y que en su virtud pase en su compañia a executar la inspeccion y reconocimiento de todo ello, y ponerlo por certificacion en la presente causa y probanza en cumplimiento de lo mandado en la Real Provision de mi comision, a peticion de la ciudad y a consecuencia de ello dichos caballeros regidores con asistencia y acompañamiento de mi el esscribano recetor pasaron a la plaza mayor de esta ciudad que /9r./ es donde se hallan las casas de ayuntamiento y sobre su portalada principal señalaron y se encuentra un escudo y blason de armas adornado, que se compone de un castillo entre dos cañas, con las barras de Aragon encima de uno y otro, y por remate una corona real, señalando en guarismo el año de mil settecientos quareinta y dos. Y en el patio de las mismas casas de la ciudad y portalada de la sala baxa de ayuntamientto se halla pintado otro escudo de armas que se compone de una caña en el medio y por remate las barras de Aragon, señalando en guarismo el año de mil seiscientos cincuenta y dos. Y el mismo escudo se encuentra sobre las puertas de la capilla, u oratorio que hay en las mismas casas de ayuntamiento como tambien en un quadro del Sanctismo [sic] con Santo Thomas de Aquino y San Buenaventura, que esta puesto sobre la puerta /9v./ de la ante sala alta de ayuntamiento de suerte que en dichos tres parages se compone dicho escudo de 
armas, de la caña en el medio y las barras de Aragon encima. Y dentro de la misma capilla, u oratorio, y parage correspondiente a la epistola, al costado del altar se halla igualmente y señalaron dichos caballeros regidores otro escudo de armas que se compone de un castillo entre dos cañas, con las barras de Aragon sobre uno y otro y por remate una corona real; estando al otro costado y parte del ebangelio las armas reales. Y en la campana de la chiminea de la alcovilla de lumbre destinada para el ayuntamiento en las mismas casas de la ciudad, asimismo señalaron y se encuentra otro escudo de armas en pintura que se compone de un castillo entre dos cañas, con las barras de Aragon sobre uno, y otro y por remate una corona real. Y en seguida de lo sobredicho saliendo dicho /10r./ caballeros regidores de las casas de la ciudad pasaron a su lonxa que está inmediata y contigua a ellas; y en el arco de una puertta que dixeron llamarse de la Corte, señalaron y se encuentra un escudo de armas grabado en una piedra que sobresale, y se compone de una caña en el medio y las barras de Aragon encima. Y el mismo escudo de armas si quiere otro semejante señalaron y se encuentra en otra portada cercana cerrada o condenada, que dixeron llamarse de los Ajusticiados. Y en la misma lonxa, y arco de la puerta llamada del Positto hay otro escudo de armas compuesto solamente de una caña grabada en una de las piedras de dicho arco: en la esquina de la misma lonja que corresponde a dicha plaza y calle Mayor señalaron y assimismo se encuentra otro escudo de armas que se compone de dos cañas labradas en una piedra, que la una de ellas corresponde y mira a dicha plaza, y la otra a la referida calle Mayor. Y en uno de los / 10v./ arcos que forman la referida lonxa assimismo señalaron, y se encuenttra otro escudo de armas compuesto de una caña solamente que está grabada en él. Y en este estado a instancia de dichos caballeros regidores rettrocedi a las casas de ayuntamientto donde se me manifestó un tablon de talla y pintura antigua que dixeron ser una de las alas del retablo mayor de la yglesia antigua de la colegial de esta ciudad, en el que esta pintado un San Matias, haviendo mas abajo y al remate del tablon un angel de talla que tiene en su mano derecha un escudo de armas compuesto de una caña al medio y las barras de Aragon encima. Y en seguida de lo sobredicho, instado /11r./ igualmentte por dichos caballeros regidores pase en su compañía a las casas de herederos de don Franco Escuin canonigo que fue de la colegial de esta ciudad y entrando a un entresuelo se encontro adornado, o enttapizado con un lienzo pintado que segun dixeron sirvio de adorno al organo de la antigua yglesia colegial de esta ciudad y que al tiempo de su demolicion se lo llebo dicho canonigo para adorno del citado entresuelo, en cuyo lienzo señalaron los mismos caballeros regidores dos escudos de armas que hay en él, que en campo rojo se componen de una caña en el medio y encima las barras de Aragon, uno y otro con pintura negra. Y en este esttado a igual instancia de dichos caballeros rexidores pase en su compañia al quartel de la presente $/ 11 v$./ ciudad y en una de las piedras que se halla en la parte superior de su portalada, señalaron y se encuentra grabado un escudo de armas que se compone de una caña tan solamente. Y en seguida de lo sobredicho a igual instancia y requerimiento pase al ferial propio de la ciudad 
existente extramuros de ella; y en una de las piedras que se halla en la parte superior de su portalada señalaron y se encuentra en igual forma grabado un escudo de armas que se compone de una caña tan solamente señalandose al pie de dicho escudo con guarismos el año de mil quinientos cincuenta y nuebe. Y despues de lo sobredicho instando assimismo por dichos caballeros regidores pase al ylador de seda propio de la ciudad que esta contiguo al combento de nuestro padre San Francisco y en una de las piedras que se hallan en la parte superior de su portalada señalaron y se encuentra otro escudo de armas que se compone de /12r./ una caña tan solamente, señalandose alli mismo con guarismo el año de mil settecientos y sesenta. Y en seguida de lo sobredicho a igual instancia de los mismos caballeros regidores pase a la cruz llamada de Alcala que esta situada extramuros de la ciudad y cercanias del portal llamado de las Herrerias; y en dicha cruz señalaron y se encuentra en la parte superior un escudo de armas que se compone de una caña en el medio y sobre ella las barras de Aragon, señalandose en la misma con guarismo el año de mil settecientos cincuenta y siette. Y continuando dichos caballeros regidores por los [palabra ilegible] de la ciudad llegaron con mi asistencia al portal llamado de San Jaime donde sobre su portada señalaron y se encuentra grabado en una piedra un escudo de arma que se compone de una caña solamente. Y en seguida pasaron al portal del Puente de esta ciudad que es camino para la de Zaragoza y en el medio del frontispicio que forma /12v./ dicho portal en la parte que mira al puente señalaron y se encuentra un escudo de armas adornado que se compone de un castillo entre dos cañas, con las barras de Aragon encima y por remate una corona real, manifesttando que la obra de dicha corona es mas moderna que lo restante, señalando en guarismo el año de mil quinientos y settenta, y en el mismo frontispicio y a los dos estremos de el señalaron y se encuentran igualmente dos escudos de armas semejantes el uno del otro que hazen o forman simetria con el antecedente y se componen de una caña tan solamente. Y continuando dichos caballeros regidores por el puente llegaron a una cruz de piedra que hay en una de sus arcadas o cuchillos, y en ella señalaron y se /13r./ encuentra una caña grabada en dicha cruz y lo mismo señalaron y se encuentra en una piramide que hay por remate del pretil de dicho puente. Y en seguida continuaron dichos caballeros regidores al molino de aceite propio de la ciudad que está cercano a dicho puente, y en la parte superior de su portada señalaron y se encuentra otro escudo de armas grabado en una piedra y se compone de una caña al medio y las barras de Aragon encima de ella, señalando con guarismo el año de mil quinientos cincuenta y seis. Y en seguimiento de ello pasaron assimismo dichos caballeros regidores a la fuente de settenta caños llamada de Santa Lucia que está cercana al mismo puente, y en la lameda [sic] del Prado y en la muralla de dicha fuente señalaron y assimismo se encuentra otro escudo de /13v./ armas que se compone de una caña en el medio y las barras de Aragon encima. Y el mismo escudo de armas señalaron y se encuentra en la portada del ylador nuevo de seda propio de la ciudad y esta en la misma lameda [sic] del Prado aumenttandose en esta con guarismos el año de mil settecientos settenta y tres. 
Y en este estado a igual instancia de dichos caballeros regidores pasé en su compañía al matadero, pescateria y ornos de cocer pan llamados nuevo y de consexo, todo propio de la ciudad y en cada una de las portadas de dichas oficinas señalaron y se encuentra un escudo de armas que se compone de una caña tan solamente. Y en seguida instado por los mismos caballeros regidores pase al hospital de esta ciudad y encima [de] la portalada de su yglesia señalaron y se encuentra un escudo de armas que se compone de una caña en el medio, y las barras de Aragon /14r./ encima. Y en este estado se curso en la presente diligencia y señalamiento de armas. Y para que conste lo firmaron dichos caballeros regidores con mi el esscribano recettor que de todo ello certifico $=$ enmiendo $\mathrm{cincu}=$ valga

[Suscripción autógrafa: Pantaleon Arcayne]

[Suscripción autógrafa: Joseph Gorrita]

1775, abril, 4

Alcañiz

Joseph Forniés, escribano receptor de la causa, realiza una inspeccion ocular a la iglesia colegial de Santa María la Mayor de Alcañiz.

AHPZ, Pleitos Civiles, J13418-1, pieza 2, ff. 8v.-14v.

\section{[Al margen: Inspeccion ocular]}

En la ciudad de Alcañiz â quatro dias del mes de abril del corriente año de mil setecientos setenta, y cinco yo el /9r./ infrascrito rezetor, â fin de practicar la inspeccion ocular que se halla pedida, y mandada hazer, haviendo pasado â la insigne colegial iglesia de la misma, y visto con la mayor reflexion y ciudado lo exterior de ellas, en parte alguna de su fabrica, ni en toda su circunferencia, halle armas, ni insignia alguna de ellas, y solo en el atrio, y puerta principal, sobre ella, y en la parte superior un ornato û adorno con una imagen de Nuestra Señora de la Asumpcion, y en la inferior devajo de una cornisa, con letras doradas una cifrada del nombre de $/ 9 v$./ Maria. Y en otra puerta menos principal, en su fachada otra imagen de Nuestra Señora con el niño en los brazos, en la parte superior, y en la inferior otra cifra del nombre de Maria, y sobre ella una corona imperial. Y continuando dicha ynspeccion ocular, entrando para ello, âl interior de la referida iglesia y su sala capitular que esta en el pabimento de la torre antigua donde se hallan las campanas, en lo alto, y en el remate de la bobeda de la citada sala se ve con toda distincion, y claridad un escudo, ô circulo con una imagen de Nuestra Señora de la Asumpcion con tiara, y llaves, y una media luna, â la parte inferior, y â los lados por adorno dos cañas. /10r./ Y subiendo, â la expresada torre en el primer cuerpo, ô descanso de ella, en lo alto, y a remate de su bobeda, un circulo de piedra y dentro una imagen de Nuestra Señora en pie con un niño en el brazo derecho, y en las quatro fajas que se desprenden, al remate y extremo de una, una caña, al de otra unas ojas de talla, y en las dos restantes, dos caras, ô, figuras de 
medio cuerpo. Y en el segundo cuerpo de la propia torre en lo alto, y remate de su bobeda otro circulo con otra ymagen de Santa Barbara, y en el terzero donde se hallan dichas campanas, no se notan armas ni insignia alguna. Y descendiendo de la enunciada torre â lo interior de la sobredicha /10v./ yglesia, en la caxa, ô frente de organo que se halla colocado sobre el coro, se ve clara y distintamente en la parte superior de el un escudo con un castillo, dos cañas, y las barras de Aragon, y en la barandilla del propio coro por la parte interior â un extremo en una pilastra de madera, y de pintura antigua otro escudo con una imagen de Nuestra Señora de la Asumpcion, tiara y llaves, y una media luna, â la parte inferior, y â los lados por adorno dos cañas, unas letras que dizen año, y los guarismos 16 sin /11r./ distinguirse otras, y al extremo de otra pilastra de la citada barandilla, de la misma pintura se divisa la mitad de otro igual escudo tan solamente por hallarse otra mitad encajonada en una columna. Y prosiguiendo dicha inspeccion en lo restante de su fabrica, capillas, y retablos que hay en ella, se advierten solo en el retablo de San Gregorio, y capilla llamada de don Miguel Valero unas armas, y escudo con morrón, una estrella, dos pinos, y dos peras. En el de Santa Anna otro escudo con un morrón, y una montaña con tres cruzes en su cumbre. En el Santa Victoria, y capilla llamada /11v./ de la casa de Ram otro escudo con un ramo, y una corona sobre el, en el frontal de dicho retablo, y en la bobeda de dicha capilla otro escudo y pendiente de el un sombrero, y cordones de cardenal, y dentro de la capilla del Santo Christo en un retablo de San Joaquin llamado de la casa de S $[i]$ erra, en el frontal otro escudo con una sierra y una mano. Y en la sacristia que hay en la misma capilla del Santo Christo, en el aguamanil, ô pila de piedra del lavatorio claramente se advierte haver en su centro, ô media caña gravada, y â los lados una cifra de Jesus, y Maria. Y continuando la relacionada inspeccion, por parte del cavildo de la referida ynsigne yglesia colegial en varios al /12r./ marios, y calaxes de la sala de el vestuario y sacristias se me pusieron de manifiesto diferentes jocalias, alaxas, y ornamentos pertenecientes, a la misma, de las que solamente se hallan tener, y que tienen armas o insignias, un caliz de la cofradia de San Antonio Abad, con una campana, otro caliz muy crezido con la insignia de dos martillos gravados y dos manoplas, otro caliz con el escudo de armas de una jarra de flores con su adorno, un vaso de plata con reliquias con un rotulo que dice Vives, otro vaso de reliquias, y en el gravado un escudo con un pino, y una barra, una campanilla y en ella gravadas las armas del sacramento, un brazo de reliquia y en el gravado un escudo con /12v./ morrón, una corona, una aguila, y una flor, tres fuentes de plata, en la una las armas del sacramento, en la otra el escudo del Carmen, y en la otra una celada ô morron con una espuela, una barra y cinco monedas, un jarro crecido gravado con un escudo con una torre, y dos flores de lis, una paz, que dize de Herbas, gravado el escudo con dos jarras de flores, dos llaves en uno de cada dos nichos año 1570, otra paz gravada en ella la insignia de una sola caña, dos cetros dorados con el escudo armas, y en el, un castillo las barras de Aragon, y dos ca /13r./ ñas a los lados, una navecilla gravado en ella el escudo con un castillo, y dos cañas, una custodia grande de tres cuerpos con dos escudos sueltos, a 
su pie y en cada uno de ellos las barras de Aragon, y una caña, dos atriles de plata crezidos, y en cada uno de ellos gravado un escudo con una imagen de Nuestra Señora de la Asumpcion con tiara y llaves, y una media luna â la parte inferior, y â los lados dos cañas, unas sacras gravado en ellas el propio escudo, una maza de plata y en ella gravados dos escudos con las mismas armas ô insignias que las anteriormente ex /13v./ presadas, y unas letras, y guarismos que demuestran el año en que se hizo, y dicen año 1616, un misal con cubiertas de terciopelo carmesi, y gravadas en unas planchas de plata, la tiara y llaves tan solamente, tres sellos de bronze con el mismo escudo de armas de la Asumpcion, tiara, llaves, media luna y dos cañas, una capa con cenefas bordadas en oro, y en su escudo dos leones, una faja, y dos castillos, un terno de tisu antiguo, y en su cenefa un escudo con las barras de Aragon, y una caña en la parte superior de el una targeta que la parte el mismo en dos mitades, ô casillas con unas letras que por estar demolidas las de la primera, no se puede distinguir lo que /14r./ dizen, pero si la de la segunda, que clara y distintamente dize: pia, otro terno de terciopelo negro con zenefas bordadas en terciopelo carmesi, y en los collares de las dalmáticas, y gremial un escudo con un castillo, quatro barras, y dos cañas, una bolsa de damasco carmesi bordada, y en ella un escudo con la ymagen de Nuestra Señora de la Asumpcion, tiara, llaves, media luna, y dos cañas, y ultimamente un pedon de espolin de oro con el propio escudo de armas. Y para que de todo ello conste, y de no haver visto en lo exterior, ê interior de la expresada ynsigne yglesia colegial, ni en sus jocalias, alaxas, y ornamentos puestas, colocadas, ni gravadas otras, ni / 14v./ mas armas, ô insignias que las que de parte de arriva quedan referidas, lo firmo, y certifico, el raso: pintura: valga

[Suscripción autógrafa: Joseph Fornies] 
